\title{
A Preliminary Attempt on Decadal Prediction of the East Asian Summer Monsoon
}

\section{Danwei Qian ( $\nabla$ qiandw12@126.com )}

Nanjing University of Information Science and Technology https://orcid.org/0000-0002-0854-2248

\section{Yanyan Huang}

Nanjing University of Information Science and Technology https://orcid.org/0000-0003-2621-0826

\section{Huijun Wang}

Nanjing University of Information Science and Technology

\section{Research Article}

Keywords: East Asian summer monsoon, Decadal prediction, Decadal increment method

Posted Date: November 16th, 2021

DOI: https://doi.org/10.21203/rs.3.rs-697966/v2

License: (1) This work is licensed under a Creative Commons Attribution 4.0 International License. Read Full License

Version of Record: A version of this preprint was published at Theoretical and Applied Climatology on March 18th, 2022. See the published version at https://doi.org/10.1007/s00704-022-04011-w. 
A Preliminary Attempt on Decadal Prediction of the East Asian Summer Monsoon

$$
\text { Danwei Qian }{ }^{1} \text {, Yanyan Huang }{ }^{1,2,3} \text {, Huijun Wang }{ }^{1,2,3}
$$
Meteorological Disaster, Ministry of Education, Nanjing University of Information Science and Technology, Nanjing 210044, China

13 Corresponding author: Yanyan Huang, huangyy@ nuist.edu.cn 
ABSTRACT

The East Asian summer monsoon (EASM) is one of the major synoptic systems that affect

17 the summer climate in China. Decadal prediction of the EASM is of great significance, yet few

18 attempts have been made by far. This study represents a preliminary attempt that uses the

19 decadal increment (DI) method to predict the decadal variability of the EASM. The 3-year

20 increment of the decadal variability is used as the predictand, and predictors are selected from

21 the previous circulation and external forcing. The predicted increment is combined with the observation three years ago to get the final prediction result. The results of cross validation and independent hindcast show that the decadal increment method can well predict decadal

24 variability of the EASM during the recent century. In particular, the decadal regime shifts of 25 the EASM are accurately captured. The decadal variability of the EASM in 2021 is further 26 predicted with two previous predictors of the leading 4-year summer DI of the South Indian 27 Ocean and the DI of the East Siberian Sea sea ice cover. The real-time prediction results show that the chance for the occurrence of strong decadal EASM would be rare in 2021 and 2022. The method developed in the present study provides a new approach for decadal prediction of 30 the EASM.

31 Keywords East Asian summer monsoon; Decadal prediction; Decadal increment method 32 


\section{Declarations}

\section{Funding}

This research was funded by the National Natural Science Foundation of China [grant number 41991283, 42088101, 42025502].

\section{Availability of data and material}

Sea ice concentration data from the Met Office Hadley are available at https://www.metoffice.gov.uk/hadobs/hadisst/data/download.html; The National Oceanic and Atmospheric Administration (NOAA) Extended Reconstructed SST v3b dataset are from https://psl.noaa.gov/data/gridded/data.noaa.ersst.v3.html; The fifth generation European Centre for Medium-Range Weather Forecasts (ECMWF) atmospheric reanalysis (ERA5) are obtained at https://www.ecmwf.int/en/forecasts/dataset/ecmwf-reanalysis-v5. The Twentieth Century Reanalysis Product v3 dataset can be downloaded at https://psl.noaa.gov/data/gridded/data.20thC_ReanV3.pressure.html.

\section{Code availability}

All the codes are programmed by NCAR Command Language. The codes are available and maintained by author.

\section{Conflicts of interest /Competing interests}

The authors declare no conflicts of interest or competing interests.

\section{Authors' contributions}

Conceptualization: D.W.Q., Y.Y.H. and H.J.W.; Methodology: Y.Y.H. and H.J.W.; Formal analysis and software: D.W.Q.; Writing - original draft preparation: D.W.Q.; Writing - review and editing: D.W.Q., Y.Y.H. and H.J.W. All authors have read and agreed to the published version of the manuscript. 
The East Asian summer monsoon (EASM) refers to the southerly winds that prevail in East Asia in summer. As a unique component of the Asian climate system, the EASM demonstrates special spatiotemporal structure and dominates climate and climate change in East Asia (Tao et al. 1987; Ding et al. 1994; Huang et al. 2004). Due to its interactions with the climate system on multiple time scales, the EASM shows large variations from intraseasonal to interdecadal scale. The interaction between the EASM and the climate system often leads to anomalies of the EASM, which can subsequently cause heavy droughts and floods in China. Such kinds of meteorological disasters impose serious impacts on people's lives and economic activities in East Asia. Therefore, reliable prediction of the EASM changes is of great significance (Huang et al. 2007; Ha et al. 2012). On the intraseasonal scale, the EASM often demonstrates 10-20day and 30-60-day oscillation patterns (Chen et al. 2001; Mao and Chan 2005; Guan and Johnny 2006). On the interannual scale, 2-year and 4-year oscillations account for a large part of the EASM variability. These intraseasonal and interannual variabilities of the EASM have remarkable impacts on summer rainfall in China and large-scale circulation in East Asia (Meehl and Arblaster 2002; Wu et al. 2008; Ding et al. 2013). Decadal climate change is defined as changes on the time scale of 10-30 year in the future. In the 20th century, the EASM has undergone significant decadal changes. The weakening of the EASM that occurred at the end of the 1970s (Wang 2001; Xue 2001; Wang 2002; Huang et al. 2004; Ding et al. 2008) was characterized by weaker than normal south-westerly winds in the surface level and at $850 \mathrm{hPa}$ and a weakened easterly jet in the upper troposphere (Hu 1997; Xu et al. 2006; Ding et al. 2008; Zhou et al. 2009). Meanwhile, the western Pacific subtropical high retreated to the east (Huang et al. 2015; Huang and Li 2015; Tong et al. 2020). At the beginning of the 1990s, the 
Corresponding to the aforementioned decadal changes in the EASM, summer precipitation in China has also experienced significant decadal changes. From the middle of the 1960s to the end of the 1970s, the rain belts in eastern China were located in North China and South China, while the Jianghuai and Yangtze river basins had less than normal precipitation. The spatial distribution of rainfall anomaly displayed a "positive-negative-positive" pattern ("+ - +" meridional pattern) along the meridional direction. In the late 1970s, following the EASM weakening, the rainfall zone shifted to the Yangtze River basin, while precipitation in North China and South China decreased. Precipitation anomaly presented a "negative-positivenegative" pattern ("- +-" pattern) along the meridional direction. By the early 1990s, with the intensification of the summer monsoon, the main rainfall zone moved northward again, and a dipole-type of rainfall pattern prevailed in eastern China with floods in the north and droughts in the south (Wang 2001; Ding et al. 2008; Si et al. 2009; Zhu et al. 2010; Huang et al. 2011; Lü et al. 2014; Ding et al. 2018).

Many scientists have conducted research to explore the mechanisms for the decadal variability of the EASM. At the end of the 1970s, it was found that a persistent interdecadal scale cooling occurred in the upper troposphere and lower stratosphere. On the one hand, it affected the cyclonic circulation anomaly in the upper levels and promoted the strengthening of the westerly winds to the south of the East Asian jet axis. On the other hand, it influenced the anticyclonic circulation anomaly in the lower levels and weakened the EASM (Yu et al. 2004, 2007). Based on results of numerical experiments, Li et al. (2008) demonstrated that the decadal weakening of the EASM is attributed to the decadal change in the tropical sea surface temperature (SST). Changes in the SST over the tropical central and eastern Pacific led to tropospheric warming above the tropical ocean in the late 1970s. At the same time, temperature in the temperate zone of continental East Asia decreased. As a result, the thermal contrast between the ocean and the land reduced, which subsequently weakened the EASM. Yu (2013) 
106 believed that the negative correlation between the phases of the Pacific Decadal Oscillation

107 (PDO) and the EASM is the reason for the decadal weakening of the EASM since the late

108 1970s. The phase change of the PDO caused SST variation in the Pacific and Indian oceans,

109 which affected the intensity of the western Pacific subtropical high and led to the anticyclone

110 anomaly over the western Pacific. As a result, the EASM was weakened (Gong and Ho 2002;

111 Dong and Xue 2016). In addition, Ding et al. (2008, 2009) found that the weakening of the

112 atmospheric heating over the Tibet Plateau since the late 1970s has effectively reduced sensible

113 heat flux transfer from the surface to the atmosphere, leading to increased snowfall in the

114 previous winter and spring. Larger than normal snow cover in the Tibet Plateau delayed the

115 formation of monsoon temperature gradient, and thereby weakened the EASM. Other factors

116 such as North Atlantic SST tripole and North Pacific Gyre Oscillation can also affect the

117 decadal variability of the EASM (Zuo et al. 2013; Ye et al. 2016).

118 In recent years, extensive attention has been focused on decadal climate prediction, which

119 potentially has great impacts on economic and social development (Meehl et al. 2014; Zhou et

120 al. 2017). Decadal climate prediction at present mainly relies on the initialized climate models,

121 yet the initial shock is still a problem in the model initialization that hasn't been fully solved

122 (Meehl et al. 2014; Zhou et al. 2017). Compared with that in the North Pacific, the initialization

123 in decadal prediction over the North Atlantic has been remarkably improved (Doblas-Reyes et

124 al. 2013; Kirtman et al. 2013). Most of the current models have demonstrated satisfactory skills

125 for prediction of the Atlantic Multidecadal Oscillation, whereas the model skills for PDO

126 prediction are generally low (Kim et al. 2012). In addition, the model performance for the

127 prediction of land surface temperature in the northern hemisphere remains poor. Compared

128 with the uninitialized prediction skills, the model performance shows no obvious improvement

129 after implementing initialization strategies (Doblas-Reyes et al. 2013; Wu et al. 2019). Also,

130 decadal prediction of precipitation by climate models still has problems. The models only show 
131 prediction skills over some areas, and the improvements are quite limited even after the 132 initialization strategy is implemented (Kirtman et al. 2013; Meehl et al. 2014; Wang et al.

133 2018). Therefore, decadal climate prediction by current climate models still remains a 134 challenging issue.

135 Based on the interannual increment approach (Fan et al. 2008; Wang et al. 2012), Huang 136 and Wang (2020a, b) proposed a decadal increment method to address climate prediction. In 137 this method, decadal signals are first obtained from moving averages of the raw data, and the 138 decadal increments are then used to identify the predictors to build the forecast model. Finally, 139 the predicted increment is combined with the previous observations to get the final prediction 140 result. This method helps to increase the effective samples and obtain more useful decadal 141 signals of the climate system from previous observations. Great progress has been made in the 142 predictions of PDO and decadal variability of summer precipitation in North China using the 143 decadal increment method. However, it still remains questionable whether this method can be 144 effectively applied to the prediction of other climate variables. Taking into account the close 145 relationship between the EASM and the summer climate in China and the limited predictive 146 skills of current climate models for precipitation and land surface temperature, this study 147 attempts to predict decadal variability of the EASM using the decadal increment method.

148 The rest of this article is organized as follows. Section 2 describes the datasets and method.

149 Section 3 introduces how to use the decadal increment to build a statistical model. The hindcast 150 skills of the statistical model based on the decadal incremental method are presented in Section

151 4. Section 5 uses this method to build a real-time prediction model to predict EASM. The 152 discussion is given in Section 6. Finally, Section 7 presents the summary.

\section{Data and methods}

Monthly mean reanalysis datasets used in this study include the following: 
155 1) Horizontal wind components ( $\mathrm{U}$ and $\mathrm{V}$ ) and geopotential height are extracted from the

156 Twentieth Century Reanalysis Product v3 (20CR) with a horizontal resolution of $1^{\circ} \times 1^{\circ}$ and

157 cover the period from 1910-2012 (Compo et al. 2011);

158 2) Sea surface temperature (SST) data with a horizontal resolution of $2^{\circ} \times 2^{\circ}$ are from the

159 National Oceanic and Atmospheric Administration (NOAA) Extended Reconstructed SST v3b

160 dataset and covers the period from 1910-2012 (Smith et al. 2008);

161 3) Sea ice cover (SIC) data are from the Met Office Hadley Centre with a horizontal resolution 162 of $1^{\circ} \times 1^{\circ}$ and covers the period from 1910-2012 (Rayner et al. 2003).

163 4) Horizontal wind components (U and V), sea surface temperature (SST) and sea ice cover 164 (SIC) are derived from the fifth generation European Centre for Medium-Range Weather 165 Forecasts (ECMWF) atmospheric reanalysis (ERA5, Hersbach et al. 2020) with a horizontal 166 resolution of $1^{\circ} \times 1^{\circ}$ and cover the period from 1980-2020.

167 The first three datasets have been chosen to calculated the EASMI in sections 3, 4 and 6, and 168 the last dataset has been used in section 5.

The EASM index (EASMI) is defined as the area-mean $\left(110-125^{\circ} \mathrm{E}, 20^{\circ} \mathrm{N}-40^{\circ} \mathrm{N}\right)$ wind speed at $850 \mathrm{hPa}$ in summer (June-July-August) (Wang 2002). Based on the decadal increment method proposed by Huang and Wang (2020a, b), the statistical model is established. First,

172 decadal EASMI is obtained from the 5-year running mean of the original EASMI and marked 173 as EASMI in the middle year of the five years. Decadal increment (DI) of the EASMI (DI_EASMI) is then calculated from decadal EASMI, that is, the decadal EASMI of the current year minus the decadal EASMI three years ago will be treated as DI_EASMI of the current year (Eq. 1). Finally, predictors are identified based on DI_EASMI and a prediction model is

177 built using these predictors. The final predicted EASMI is the predicted DI_EASMI plus the observed EASMI three years ago (Eq. 2). For example, the final predicted EASMI in 1924 is 
obtained by adding the predicted DI_EASMI in 1924 to the observed EASMI in 1921. Similar to the DI of the predictand, the DI of the predictor is obtained by performing the 5-year running mean first and then calculating the 3-year increment. To avoid possible containing of the information of the prediction period in the predictors, the predictors have to lead the predictand by at least three years. For example, the summer DI of the SST (DI_SST) from 1918 to 2007 and the DI_EASMI from 1921 to 2010 are used for correlation analysis to find key predictors, and so on.

$$
D I_{-} E A S M I_{i}=E A S M I_{i}-E A S M I_{i-3}
$$

$$
E A S M I_{i}=E A S M I_{i-3}^{o b s}+D I_{-} E A S M I_{i}^{\text {pre }}
$$

\footnotetext{
In order to judge whether climate variables follow normal distribution, the skewness coefficient (g1) and kurtosis coefficient (g2) are calculated.
}

$$
\begin{gathered}
g 1=\sqrt{\frac{1}{6 n}} \sum_{i=1}^{n}\left(\frac{x_{i}-\bar{x}}{s}\right)^{3} \\
g 2=\sqrt{\frac{n}{24}}\left[\frac{1}{n} \sum_{i=1}^{n}\left(\frac{x_{i}-\bar{x}}{s}\right)^{4}-3\right]
\end{gathered}
$$

192 Where $\mathrm{n}$ is the number of the sample, $\overline{\mathrm{x}}$ and $\mathrm{s}$ are the mean and standard deviation of the 193 sample. The skewness coefficient characterizes the degree to which the peak of the curve deviates from the mean value. A positive $\mathrm{g} 1$ indicates that the mean is to the left of the peak, and a negative $\mathrm{g} 1$ indicates that the mean is to the right of the peak. The kurtosis coefficient characterizes the convexity of the peak of the distribution pattern and measures the degree of concentration of the frequency distribution. A positive g2 indicates that the frequency distribution is more concentrated than the normal distribution, and the average is more representative, and a negative $\mathrm{g} 2$ is the opposite. 
Cross validation and independent hindcast are used to verify the predictive skill of the established empirical statistical model. In the cross validation, the EASM observational data for the period 1921-2010 and the predicted EASM data three/four/five years ahead of the observation time are selected first, and the 5-year data centred on the target year are excluded.

The data in the remaining years are then used to build the model to predict the EASM in the target year. This process is repeated for each target year. The first and last three years of the data are verified by leaving the first and last five years of data out. The independent hindcast uses the same observational data. To avoid using the information of the prediction period, the data from the starting year to three years ahead of the target year are used as the training samples to establish the empirical statistical model to predict the situation in the target year. The aforementioned process is repeated for 1980-2010. For example, if the target year is 1990 (1991), the data from 1921-1987 (1921-1988) is used to build the prediction model. transitions of decadal variation of the EASM, and the significance of the correlation coefficient is tested by Student's t-test. The effective sample size $\mathrm{N}^{*}$ is computed (Bretherton et al. 1999):

$$
N^{*}=N \frac{1-r_{x} r_{y}}{1+r_{x} r_{y}}
$$

216 Where $\mathrm{N}$ is the number of available time steps, and $\mathrm{r}_{\mathrm{x}}$ and $\mathrm{r}_{\mathrm{y}}$ are the autocorrelation coefficients 217 of the two correlated variables lagging one step behind.

218 The mean square skill score (MSSS) is used to test the predictive skill of the model 219 (Murphy, 1988; Goddard et al. 2012). The MSSS algorithm is written as:

$$
\begin{gathered}
M S S S=1-\frac{M S E}{M S E_{C}} \\
M S E=\frac{1}{n} \sum_{i=1}^{n}\left(f_{i}-o_{i}\right)^{2}
\end{gathered}
$$




$$
M S E_{C}=\frac{1}{n} \sum_{i=1}^{n}\left(o_{i}-\bar{o}\right)^{2}
$$

Where fi and $o_{i}$ represent the time series of observations and forecasts, respectively. MSSS reflects the percentage reduction of the mean square error (MSE) predicted by the statistical model, and $\mathrm{MSE}_{\mathrm{C}}$ is the MSE of the "climatological forecast". A positive MSSS indicates that the statistical model prediction is better than that of the "climatological forecast", and a negative MSSS indicates that the model forecast is inferior to the "climatological forecast".

\section{Prediction model}

Based on the definition of the EASMI, decadal EASMI is calculated. The time series of EASMI for the period 1918-2010 is displayed in Fig. 1a, which shows that the EASM was in a positive phase from 1920 to the mid-1930s and then switched to a negative phase from the mid-1930s to the mid-1940s. The EASM was relatively strong during the period from the 1950s to the 1970s, but it suddenly weakened at the end of the 1970s. This result is consistent with studies of Wang (2001), Guo et al. (2003), Huang et al. (2004) and Ding et al. (2008). In the early 1990s, the EASM began to intensify again. This phenomenon is also found in Liu et al. (2012) and Ding et al. (2013).

The basic assumption of climate statistics analysis is that the climate variables follow a normal distribution. When the skewness coefficient (g1) and kurtosis coefficient (g2) of the data are both less than 1.96 , the data can be treated as following normal distribution at the $95 \%$ confidence level. For the decadal EASMI (Fig. 2), both the skewness coefficient and the kurtosis coefficient are higher than 1.96, which means right shifting skewness distribution than normal distribution and steeper kurtosis distribution. The 1-year and 2-year increments of decadal EASMI are also not satisfy the normal distribution. Interestingly, the 3-year increment 
244 follows normal distribution at the 95\% confidence level (Fig. 2). Therefore, the 3-year increment is selected for further analysis. Time series of 3-year increment is shown in Fig. 1b.

This paper implements the decadal increment method and uses the predictors in the decadal increment form to establish the empirical statistical model for DI_EASMI prediction. First, based on findings of previous studies, potential predictors are identified from SST, SIC and circulation fields, etc. To avoid possible containing of the information during the prediction period in the predictors, the predictors need to lead the DI_EASMI by at least three years. The stepwise regression method is then used to select the predictors that are significantly related to DI_EASMI and are independent of each other. The finally built prediction model is expressed by:

$$
D I \_E A S M I=0.50 * D I+S S T I+0.41 * D I_{-} B H+0.30 * D I I_{-} S I C
$$

the DI of the sea surface temperature index (DI_SSTI), the DI of the Bonin high (DI_BH) and the DI of the sea ice cover (DI_SIC) explain 25\%, 17\%, and 9\% of the DI_EASMI variance, respectively.

The first predictor selected in this paper is the tropical ocean temperature signal in summer that leads DI_EASMI by three years. Fig. 3a shows the spatial pattern of the correlation coefficient between DI_SST and DI_EASMI for the period 1921-2010. The colder equatorial western Pacific and the warmer equatorial central and eastern Pacific are conducive to the enhancement of DI_EASMI. Physically, the equatorial central and eastern Pacific warming is favorable for the EASM intensification because anomalous ascending motions develop above the equatorial central-eastern Pacific while descending motions occur over the subtropical western Pacific. The above circulation is the so-called "quasi-Walker circulation" (Ying and Sun 2000; Wu et al. 2003; He et al. 2015). Additionally, the western Pacific cooling can strengthen the EASM through changing in-situ precipitation and further triggering descending atmospheric Rossby waves (Zhang et al. 1999; Wang et al. 2000; Wang et al. 2013; Huang et 
al. 2018). To quantify this characteristic relationship, area-weighted regionally averaged DI_SST in these two regions (multiplied by -1 in the negative region) is defined as the sea surface temperature index (DI_SSTI). The ranges of positive and negative regions are $\left(10^{\circ} \mathrm{S}-\right.$ $\left.4^{\circ} \mathrm{N}, 170^{\circ} \mathrm{E}-160^{\circ} \mathrm{W}\right)$ and $\left(0^{\circ}-16^{\circ} \mathrm{N}, 129^{\circ} \mathrm{E}-155^{\circ} \mathrm{E}\right)$, respectively.

The second predictor is the leading 4-year autumn Bonin high $\left(32^{\circ} \mathrm{N}-50^{\circ} \mathrm{N}, 130^{\circ} \mathrm{E}-165^{\circ} \mathrm{E}\right)$, which is an anticyclone over Japan (Fig. 3b). As a possible descending branch of the Hadley cell, the Bonin high (1) can induce a meridional overturning and PJ pattern is established (Enomoto et al. 2003; Hsu and Lin 2007; He et al. 2018). There is an anomalous strong westward flow on the south of the Bonin high, which makes humid in East Asia and the EASM increases accordingly (Wakabayashi and Kawamura 2004; Yasunaka and Hanawa 2006; Ming et al. 2019).

The third predictor is the leading 5-year Kara Sea SIC $\left(77^{\circ} \mathrm{N}-80^{\circ} \mathrm{N}, 70^{\circ} \mathrm{E}-90^{\circ} \mathrm{E}\right)$ in summer (Fig. 4a). The changes of SIC are highly correlated with the variability of the EASM (Zhao et al. 2004; Wu et al. 2009a, b; Guo et al. 2013; Li et al. 2018; Lin and Li 2018). The SIC anomaly is closely related to changes in the extent of Eurasia snow cover (Fig. 4b) (Cohen et al. 2012; Li et al. 2018), which has an impact on EASM (Wu et al. 2009c) through affecting the soil moisture (Zhang and Zuo 2011). The reduction in SIC over the Kara Sea also may trigger an anomalous high in summer (Fig. 4c) through the European land surface acting as a "bridge". The EASM is prevented from moving northward by the anomalous high and weakens (Zhao et al. 2004).

Fig. 5 shows time series of DI for each predictor and DI_EASMI. The correlation coefficients of DI_EASMI with DI_SIC,DI_SSTI and DI_BH are $0.67,0.47$ and 0.59 , respectively, all of which are significant at the $99 \%$ confidence level by the student's t-test. Due to the long study period, the correlation between each predictor and DI_EASMI may present decadal changes. The correlation between the Bonin high and the EASMI changed 
294 abruptly at the end of the 1950s, and a weak correlation remained until the end of the 1970s

295 (Fig. 6a). In addition to the weak correlation between DI_SSTI and DI_SIC occurred around 1980, the correlation remained stable in other years (Fig. 6b, c). Therefore, on the whole, the three predictors are stably and significantly correlated with DI_EASMI across the study period.

\section{Prediction effect}

To evaluate the performance of the established statistical model, cross validation and independent hindcast are conducted in the present study. Results of the cross validation are displayed in Fig. 7a, which shows that the correlation coefficient between the predicted DI_EASMI and the observation for the period $1921-2010$ is 0.81 , which is significant at the $99 \%$ confidence level by the student's t-test. MSSS is 0.65 . The predicted DI_EASMI well captures the variability shown in observations during the study period except for the mid-1950s and the 1970s, when decadal variability of the related relationships occurred. This result indicates that the empirical statistical model developed in the present study has a high predictive skill. The DI_EASMI predicted by the empirical statistical model is added to the leading 3-year observed EASMI to obtain predicted decadal EASMI. Except for the inconsistency that existed in the mid-1950s and the 1970s, the predicted EASMI realistically reproduces the positive phase over the period from the 1920 s to the 1930 s, the negative phase

311 from around the late 1930s to the 1940s, the positive phase since the 1960s, the weaker EASM

312 in the 1980s, and the intensification of the EASM in the early 1990s. The amplitude of the

313 EASM oscillation is also quite consistent with observations. Furthermore, the correlation

314 coefficient between the observed and predicted EASMI is 0.90 and MSSS is 0.78 (Fig. 7b and

315 Table 1). In addition, the predicted EASMI well captures the regime shifts of the EASM due

316 to its intensification in the 1940s and its weakening in the 1960s and 1970s as well as its

317 intensification in the early 1990s. The prediction errors for these regime shifts all are less than 
three years (Fig. 7c). The above results show that the decadal increment method has a high hindcast skill.

The hindcast skill is further verified based on the independent hindcast of the DI_EASMI from 1980 to 2010 . Fig. $7 d$ shows that the variability displayed in observations is accurately grasped, and the correlation coefficient between the observed and the predicted DI_EASMI is 0.91 , which is above the $99 \%$ confidence level by the student's t-test. MSSS is 0.81 . The variability and amplitude of the predicted EASMI are quite consistent with observations, including the transition from negative to positive EASMI in the early 1990s. The correlation coefficient between the observations and predictions of the EASMI is 0.87 , and MSSS is 0.72

(Fig. 7e and Table 1). In addition, the predicted EASMI accurately captures the regime shift of the EASM in the early 1990s (Fig. 7f). Therefore, results of cross validation and independent hindcast indicate that the empirical statistical model combined with the decadal incremental method has a high skill of prediction for decadal variability of the EASM. The decadal regime shifts of the EASM can also be well captured.

\section{The real-time prediction for EASM in 2021}

Through the above analysis, it is found that the decadal increment method can effectively predict the long-term EASM. In this section, we operate a real-time prediction for EASMI in 2021. The statistical forecast model is rebuilt for two main reasons. One is that there is few dataset covering the period from current to hundred years ago. The 20CR datasets used in above section ends at 2015. Therefore, we change to use the ERA5 dataset to operate the real-time prediction in this section. The other reason is that the relationship of the DI_EASMI with DI_SIC (DI_BH) has weakened after 2010 (2004) (Fig. S1). The predictive skill of the Eq. 9 for the DI_EASMI becomes not reasonable during recent decade (Fig. S2). It is not surprised that the relationships between prediction and predictors have decadal shifts under the 
background of many decadal shifts occurred in the climate (Krishnamurthy and Krishnamurthy 2016; Notz 2017; Huang et al. 2018; Xu et al. 2019; Cai et al. 2021).

$$
D I \_E A S M I=-0.85 * D I \_S I C-0.37 * D I \_S S T
$$

The leading 4-year summer East Siberian Sea sea ice cover $\left(71^{\circ}-76^{\circ} \mathrm{N}, 150^{\circ}-178^{\circ} \mathrm{E}\right)(\mathrm{Fig}$.

8a) and leading 4-year summer South Indian Ocean (SIO) sea surface temperature $\left(35^{\circ}-44^{\circ} \mathrm{S}\right.$, $70^{\circ}-110^{\circ} \mathrm{E}$ ) by removing the effect of East Siberian Sea sea ice cover (Fig. 9) are selected as predictors, which explain $72 \%$ and $14 \%$ of the DI_EASMI variance, respectively. This indicates that the selected predictors can roughly reflect the characteristics of the EASM. The correlation coefficients of DI_EASMI with DI_SIC and DI_SST are 0.85 and 0.37 , respectively, both of which are significant at the $95 \%$ confidence level by the student's t-test. Their relationships have remained steady during most of the study period (Fig. 10), so they are selected as predictors.

Physically, the Arctic SIC is contributed to the EASM as previously discussed. As shown in Fig. 8b, the anomaly of sea ice in the East Siberian Sea possibly impacts SST anomalous in the North Pacific by affecting atmospheric circulation, which can persist into summer and influence the EASM circulation and precipitation (Guo et al. 2014). In addition, the SIO SST anomaly has an important impact on the interdecadal changes of the EASM at the end of the 20th century (Xue 2001; Zhang et al. 2017). The decadal cooling in the SIO may lead to anomalous mid-tropospheric descents over the western SIO and anomalous ascents over the eastern SIO and the tropical Indian Ocean. The upper-level divergent flows converge over tropical East Asia, an anomalous low-level anticyclone is observed over the South China SeaPhilippines, thereby enhancing the EASM (Zhang et al. 2017).

In the cross validation, the correlation coefficient between the predicted DI_EASMI and the observation for the period 1990-2018 is 0.90 and MSSS is 0.81 (Fig. 11a). The predicted 
DI_EASMI is added to the leading 3-year observed EASMI to obtain predicted EASMI. The correlation coefficient between the observed and predicted EASMI is 0.90 and MSSS is 0.78 (Fig. 11b). In addition, the predicted EASMI well captures the regime shift of the EASM in the early 2000s (Fig. 11c). In the independent hindcast, the correlation coefficient between the observed and the predicted DI_EASMI is 0.90 during 2011-2018, and MSSS is 0.79 (Fig. 11d). The correlation skill of the final predicted EASMI is 0.94, along with an MSSS of 0.87 (Fig. $11 \mathrm{e})$.

Regardless of cross validation or independent hindcast, the prediction model shows almost consistent results with observations, which increases our confidence in predicting future changes of EASM. According to the results of independent hindcast, EASM is relatively weak in 2019 and 2020, but it is likely to be a weak positive phase in 2021 (Fig. 11e). To explore whether 2021 will be a decadal regime shift, EASM in 2022 is further calculated. Different from the previous method, we consider using the predicted DI_EASMI from the statistical model added to the prediction of EASMI three years ago from decadal increment method to get the re-predicted EASMI in 2022. This method was tested and the results show that the correlation coefficient between the re-predicted EASMI and the observation is 0.78 and MSSS is 0.51 , and the variability of the predicted value is relatively consistent with observations (Fig. 12). Therefore, EASM in 2022 is predicted by this method and it may return to a negative phase (Fig. 11e and Fig. 12), which means the chance of a decadal regime shift is relatively rare.

\section{Discussion}

To compare with the decadal increments method, the empirical statistical model in the original form is established, and the predictors are selected over the same areas as that selected for the decadal increment model (Eq. 9).

$$
E A S M I=0.41 * S S T I+0.39 * B H+0.48 * S I C
$$


390 The correlation coefficients of decadal EASMI during the period 1921-2010 with the SIC, BH 391 and sea surface temperature index (SSTI) are $0.51,0.37$, and 0.66 , respectively. Results of the

392 cross validation show that the correlation coefficient between observations and predictions of 393 the EASMI by the empirical statistical model in the original form is 0.67 and MSSS is 0.43

394 (Fig. 13a and Table 1), both of which are lower than that between observations and forecast of 395 the empirical statistical model for decadal increment prediction (correlation coefficient and 396 MSSS are 0.90 and 0.78 respectively). The empirical statistical model in the original form fails to capture the EASM variability, although it reproduces the negative phase around 1940, the positive phase in the early 1960s, the negative phase in the 1980s and the positive phase in the early 1990s (Fig. 13a). The model also cannot effectively capture the decadal regime shifts of the EASM (Fig. 13b). In the independent hindcast, the correlation coefficient between the predicted and the observed EASM from 1980 to 2010 is 0.76 (Fig. 13c and Table 1) and the decadal regime shift in the early 1990s is accurately grasped (Fig. 13d). However, the negative phase that began in the mid-1990s was mistakenly predicted as a positive phase, and MSSS is -1.39 (Table 1). This result indicates that the hindcast skill of the statistical model is quite limited. Therefore, using the decadal increment method to build a statistical model is helpful to improve the skill for the EASM prediction.

\section{Summary}

Based on previous research of decadal changes in the EASM and analysis of the relationship between the DI of predictors and DI_EASMI, the present study develops the empirical statistical prediction model that is combined with the decadal increment method to

411 predict decadal variability of the EASM.

The statistical model is valuable when the relationships between the predictant and the predictors remain stable during the study period. The process of model building is illustrated 
414 in Fig. 14. First, based on the 5-year running mean EASMI, the 3-year decadal DI_EASMI is

415 calculated, that is, the running mean EASMI of the current year minus the EASMI three years

416 ago. The leading 3-year summer DI_SSTI over the equatorial Pacific, the leading 4-year

417 DI_BH in autumn and the leading 5-year summer DI_SIC over the Kara Sea are then selected

418 as predictors. Note that these predictors remain independent of each other. Compared with the

419 method of selecting the original variables directly, the incremental method increases effective samples in the correlation analysis and obtains more useful decadal signals in the climate system from previous observations. Finally, the selected predictors are used to build the statistical model, and the final predicted EASMI is the predicted DI_EASMI plus the observed EASMI three years ago. Results of cross validation from 1921 to 2010 indicate that the variability and amplitude of the predicted EASMI are quite consistent with the observed EASMI. Their correlation coefficient is 0.90 , and MSSS is 0.78 . The independent hindcast during the period 1980 to 2010 also shows that the variability and amplitude of the predicted EASMI are consistent with the observed EASMI. Their correlation coefficient is 0.87 , and MSSS is 0.72 . In addition, the predicted EASMI accurately captures the decadal regime shifts. The above results indicate that the decadal incremental method can well reproduce the characteristics of decadal variability of the EASM. Compared with the statistical model in the original form, the prediction skills of the model developed in this study are also improved, which makes it a great tool for future prediction of decadal changes in the EASM. EASM in 2021 and 2022, the leading 4-year summer DI of the South Indian Ocean (SIO) sea surface temperature and the leading 4-year summer DI of the East Siberian Sea sea ice cover are selected as predictors. The results show that EASM is in a negative phase in 2019 and 2020, but it may be in a weak positive phase in 2021 and will go back to a negative phase in 
439 Using the decadal increment method, preliminary attempts have been made to predict 440 decadal variability in the EASM, and satisfactory results have been achieved. This study 441 provides a new solution for the prediction of decadal variability. In the future, machine learning 442 combined with this method can replace multiple linear regression for the prediction of other 443 climate phenomena, such as decadal variability of drought in North China. Since the predictive 444 effect of the decadal increment method is better than that of the original form, it can also be 445 applied for decadal prediction in climate dynamic models, which may further improve the 446 predictive skill of climate models. 
449 Bretherton CS, Widmann M, Dymnikov VP, Wallace JM, Bladé I (1999) The effective number 450 of spatial degrees of freedom of a time-varying field. J Clim 12(7):1990-2009. https://doi.org/10.1175/1520-0442(1999)012<1990:TENOSD>2.0.CO;2.

Cai QQ, Beletsky D, Wang J, Lei RB (2021) Interannual and decadal variability of Arctic summer sea ice associated with atmospheric teleconnection patterns during 1850-2017. $J$ Clim 1-89. https://doi.org/10.1175/JCLI-D-20-0330.1.

Chen LX, Zhu CW, Wang W, Zhang PQ (2001) Analysis of the Characteristics of 30-60 Day Low-Frequency Oscillation over Asia during 1998 SCSMEX. Adv Atmos Sci 18:623-638. https://doi.org/10.1007/s00376-001-0050-0.

Cohen JL, Furtado CJ, Barlow MA, Alexeev VA, Cherry JE (2012) Arctic warming, increasing snow cover and widespread boreal winter cooling. Environ Res Lett, 7:014007. https://doi.org/10.1088/1748-9326/7/1/014007.

Compo GP, et al (2011) The Twentieth Century Reanalysis Project. Quart J Roy Meteor Soc 462 137(654):1-28. https://doi.org/10.1002/qj.776.

Ding YH (1994) Monsoon over China. Netherlands: Kluwer Academic Publishers, 420.

Ding YH, Wang ZY, Sun Y (2008) Inter-decadal variation of the summer precipitation in East China and its association with decreasing Asian summer monsoon. Part I: observed evidences. Int J Climatol 28:1139-1161. https://doi.org/10.1002/joc.1615.

Ding YH, Sun Y, Wang ZY, Zhu YX, Song YF (2009) Inter-decadal variation of the summer precipitation in China and its association with decreasing Asian summer monsoon Part II: Possible causes. Int J Climatol 29(13):1926-1944. https://doi.org/10.1002/joc.1759. 
Ding YH et al (2013) Interdecadal and interannual variabilities of the Asian summer monsoon and its projection of future change. Chin J Atmos Sci 37 (2):253-280. https://doi.org/10.3878/j.issn.1006-9895.2012.12302. (in Chinese)

Ding YH et al (2018) On the characteristics, driving forces and inter-decadal variability of the East Asian summer monsoon. Chin J Atmos Sci 42 (3):533-558. https://doi.org/10.3878/j.issn.1006-9895.1712.17261. (in Chinese)

Doblas-Reyes FJ et al (2013) Initialized near-term regional climate change prediction. Nat Commun 4:1715. https://doi.org/10.1038/ncomms2704.

Dong X, Xue F (2016) Phase transition of the Pacific decadal oscillation and decadal variation of the East Asian summer monsoon in the 20th century. Adv Atmos Sci 33(3):330-338. https://doi.org/10.1007/s00376-015-5130-7.

Enomoto T, Hoskins BJ, Matsuda Y (2003) The formation mechanism of the Bonin high in August. Quart J Roy Meteor Soc 157-178. https://doi.org/10.1256/qi.01.211.

Fan K, Wang HJ, Choi YJ (2008) A physically-based statistical forecast model for the middlelower reaches of the Yangtze River Valley summer rainfall. Chin Sci Bull 53(4):602-609. https://doi.org/10.1007/s11434-008-0083-1.

Goddard L et al (2012) A verification framework for interannual-to-decadal predictions experiments. Clim Dyn 40:245-272. https://doi.org/10.1007/s00382-012-1481-2.

Gong DY, Ho CH (2002) Shift in the summer rainfall over the Yangtze River valley in the late 1970s. Geophys Res Lett 29(10):78-71-78-74. https://doi.org/10.1029/2001GL014523.

Guan B, Chan JCJ (2006) Nonstationary of the intraseasonal oscillations associated with the Western North Pacific summer monsoon. J Clim 19:622-629. https://doi.org/10. 1175/JCLI3661.1. 
493 Guo D et al (2013) Mechanism on how the spring Arctic sea ice impacts the East Asian summer monsoon.

Theor

Appl

Climatol

115(1-2):107-119. https://doi.org/10.1007/s00704-013-0872-6.

Guo QY, Cai JN, Shao XM, Sha WY (2003) Interdecadal variability of East Asian summer monsoon and its impact on the climate of China. Acta Geol Sin 58:569-576. https://doi.org/10.3321/j.issn:0375-5444.2003.04.011. (in Chinese)

Ha KJ, Heo KY, Lee SS, Yun KS, Jhun JJ (2012) Variability in the East Asian monsoon: a review. Meteorol Appl 19:200-215. https://doi.org/10.1002/met.1320.

He C, Zhou TJ, Wu B (2015) The Key Oceanic Regions Responsible for the Interannual Variability of the Western North Pacific Subtropical High and Associated Mechanisms. $J$ Meteor Res 29(4):562-575. https://doi.org/10.1007/s13351-015-5037-3.

Hersbach H et al (2020) The ERA5 global reanalysis. Quart J Roy Meteor Soc 146:1999-2049. https://doi.org/10.1002/qj.3803.

Hsu HH, Liu X (2003) Relationship between the Tibetan Plateau heating and East Asian

rainfall.

Geophys

Res

Lett

30:2066.

Hu Z (1997) Interdecadal variability of summer climate over East Asia and its association with $500 \mathrm{hPa}$ height and global sea surface temperature. $J$ Geophys Res Atoms 102(D16):19403-19412. https://doi.org/10.1029/97JD01052.

Huang RH, Chen W, Yang BL, Zhang RH (2004) Recent advances in studies of the interaction between the East Asian winter and summer monsoons and ENSO cycle. Adv Atmos Sci 21(3):407-424. https://doi.org/10.1007/BF02915568. China. In: Chang CP (ed) East Asian Monsoon. World Scientific, pp 564. 
Huang RH, Chen JL, Huang G (2007) Characteristics and variations of the East Asian monsoon system and its impacts on climate disasters in China. Adv Atmos Sci 24(6):993-1023. https://doi.org/10.1007/s00376-007-0993-x.

Huang RH, Chen JL, Liu Y (2011) Interdecadal variation of the leading modes of summertime precipitation anomalies over eastern China and its association with water vapor transport over East Asia. Chin J Atmos Sci 35 (4):589-606. https://doi.org/10.3878/j.issn.10069895.2011.04.01. (in Chinese)

Huang YY, Li XF (2015) The interdecadal Variation of the western Pacific subtropical high as measured by $500 \mathrm{hPa}$ eddy geopotential height. Atmos Ocean Sci Lett 8:371-375. https://doi.org/10.3878/AOSL20150038.

Huang YY, Wang HJ, Fan K, Gao YQ (2015) The western pacific subtropical high after the 1970s: westward or eastward shift? Clim Dyn 44(7-8):2035-2047. https://doi.org/10.1007/s00382-014-2194-5.

Huang YY, Wang B, Li XF, Wang HJ (2018) Changes in the influence of the western Pacific subtropical high on Asian summer monsoon rainfall in the late 1990s. Clim Dyn 51:443455. https://doi.org/10.1007/s00382-017-3933-1.

Huang YY, Wang HJ (2020a) A Possible Approach for Decadal Prediction of the PDO. $J$ Meteor Res 34(1):63-72. https://doi.org/10.1007/s13351-020-9144-4.

Huang YY, Wang HJ (2020b) Is the Regional Precipitation Predictable in Decadal Scale? A Possible Approach for the Decadal Prediction of the Summer Precipitation Over North China. Earth Space Sci 7(1). https://doi.org/10.1029/2019EA000986.

Kim HM, Webster PJ, Curry JA (2012) Evaluation of short-term climate change prediction in multi-model CMIP5 decadal hindcasts. Geophys Res Lett 39:L10701. https://doi.org/10.1029/2012GL051644. 
541 Kirtman B et al (2013) Near-term climate change: Projections and predictability. In Climate $542 \quad$ change 2013: The physical science basis: Working Group I Contribution to the Fifth Assessment Report of the Intergovernmental Panel on Climate Change. Cambridge University Press, 953-1028.

Krishnamurthy L, Krishnamurthy V (2016) Decadal and interannual var- iability of the Indian Ocean SST. Clim Dyn 46(1-2):57-70. https://doi.org/10.1007/s00382-015-2568-3.

Li HM, Dai AG, Zhou TJ, Lu J (2008) Responses of East Asian summer monsoon to historical SST and atmospheric forcing during 1950-2000. Clim Dyn 34(4):501-514. https://doi.org/10.1007/s00382-008-0482-7.

Li HX, Chen HP, Wang HJ, Sun JQ, Ma JH (2018) Can Barents sea ice decline in spring enhance summer hot drought events over north-eastern China? J. Clim 31(12):4705-4725. https://doi.org/10.1175/JCLID17-0429.1.

Liu HW, Zhou TJ, Zhu YX, Lin YH (2012) The strengthening East Asia summer monsoon 554 since the early 1990s. Chin Sci Bull 57(13):1553-1558. https://doi.org/10.1007/s114340124991-8.

Lin Z, Li F (2018) Impact of interannual variations of spring sea ice in the Barents Sea on east Asian rainfall in June. Atmos Ocean Sci Lett 11:275-281.

Lü JM, Zhu CW, Ju JH, Lin X (2014) Interdecadal variability in summer precipitation over 560 https://doi.org/10.1080/16742834.2018.1454249. 
564 Meehl GA, Arblaster JM (2002) The tropospheric biennial oscillation and Asian-Australian

565 monsoon rainfall. $J$ Clim 15:722-744. https://doi.org/10.1175/15200442(2002)015<0722:TTBOAA >2.0.CO;2.

567

568

569

570

571

572

573

574

575

576

577

578

579

580

581

582

583

584

585

586

587

Meehl GA et al (2014) Decadal climate prediction: An update from the trenches. Bull Amer Meteor Soc 95(2):243-267. https://doi.org/10.1175/BAMS-D-12-00241.1.

Ming J, Sun JQ, Yu S (2019) Combined impact of the pacific-japan pattern and mediterraneannorthern eurasia pattern on east asian summer temperatures. Atmos Ocean Sci Lett 12(3): 1-10. https://doi.org/10.1080/16742834.2019.1585101.

Murphy AH (1988) Skill scores based on the mean square error and their relationships to the correlation coefficient. Mon Weather Rev 116(12):2417-2424. https://doi.org/10.1175/1520-0493(1988)116<2417:SSBOTM>2.0.CO;2.

Notz D (2017) Arctic sea ice seasonal-to-decadal variability and long- term change. Past Glob Changes Mag 72:14-9. https://doi.org/10.22498/pages.25.1.14.

Rayner NA et al (2003) Global analyses of sea surface temperature, sea ice, and night marine air temperature since the late nineteenth century. J Geophys Res Atoms 108(D14):4407. https://doi.org/10.1029/2002JD002670.

Si D, Ding YH, Liu YJ (2009) Decadal northward shift of the Meiyu belt and the possible cause. Chin Sci Bull 54(24):4742-4748. https://doi.org/10.1007/s11434-009-0385-y.

Smith TM, Reynolds RW, Peterson TC, Lawrimore JH (2008) Improvements to NOAA's historical merged land-ocean surface temperature analysis (1880-2006). J. Clim 21(10):2283-2296. https://doi.org/10.1175/2007JCLI2100.1.

Tao SY, Chen LX (1987) A review of recent research on the East Asian summer monsoon in China. In: Chang CP, Krishnamurti TN (ed) Monsoon Meteorology. Oxford University Press, pp 60-92. 
588 Tong Q, Huang YY, Duan MK, Zhao QF (2020) Possible contribution of the pdo to the 589 eastward retreat of the western pacific subtropical high. Atmos Ocean Sci Lett 100005. $590 \quad$ https://doi.org/10.1016/j.aosl.2020.100005.

591 Vihma T (2014) Effects of Arctic Sea Ice Decline on Weather and Climate: A Review. Surv. Geophys 35(5):1175-1214. https://doi.org/10.1007/s10712-014-9284-0.

Wakabayashi S, Kawamura R (2004) Extraction of Major Teleconnection Patterns Possibly Associated with the Anomalous Summer Climate in Japan. J Meteorol Soc Japan

Wang B, Wu RG, Fu XH (2000) Pacific-East Asian teleconnection: how does ENSO affect 82(6):1577-1588. https://doi.org/10.2151/jmsj.82.1577. East Asian climate? J Clim 13:1517-1536. https://doi.org/10.1175/1520$\underline{0442(2000) 013<1517: \text { PEATHD>2.0.CO;2. }}$

Wang B, Xiang BQ, Lee JY (2013) Subtropical High predictability establishes a promising way for monsoon and tropical storm predictions. P Natl A Sci 110:2718-2722.

Wang B et al (2018) Toward Predicting Changes in the Land Monsoon Rainfall a Decade in 603 Advance. J. Clim 31:2699-2714. https://doi.org/10.1175/JCLI-D-17-0521.1.

Wang HJ, Zhou GQ, Zhao Y (2000) An effective method for correcting the seasonalhttps://doi.org/10.1073/pnas.1214626110.

Wang HJ (2001) The weakening of the Asian monsoon circulation after the end of 1970's. Adv Atmos Sci 18:376-386. https://doi.org/10.1007/BF02919316. Atmos Sci 19:1-11. https://doi.org/10.1007/s00376-002-0029-5. 
611 Wang HJ et al (2012) Initiating and applying the interannual increment prediction approach

612 Advances in Climate Prediction Theory and Technique of China. China Meteorological 613 Press, pp 120-139. (in Chinese).

614 Wu BY, Zhang RH, Ding YH, D’Arrigo R (2008) Distinct modes of the East Asian summer 615 monsoon. J. Clim 21:1122-1138. https://doi.org/10.1175/2007JCLI1592.1.

616 Wu BY, Zhang RH, Wang B, D’Arrigo R (2009a) On the association between spring Arctic 617 sea ice concentration and Chinese summer rainfall. Geophys Res Lett 36(9). $618 \quad$ https://doi.org/10.1029/2009GL037299.

619 Wu BY, Zhang RH, Wang B (2009b) On the association between spring Arctic sea ice 620 concentration and Chinese summer rainfall: A further study. Adv Atmos Sci 26(4):666-678. $621 \quad$ https://doi.org/10.1007/s00376-009-9009-3.

622 Wu BY, Yang K, Zhang RH (2009c) Eurasian snow cover variability and its association with 623 summer rainfall in China. Adv Atmos Sci 26(1):31-44. https://doi.org/10.1007/s00376$\underline{009-0031-2 .}$

Wu B, Zhou TJ, Li C, Müller WA, Lin J (2019) Improved decadal prediction of NorthernHemisphere summer land temperature. Clim Dyn 53:1357-1369. https://doi.org/10.1007/s00382-019-04658-8.

Wu GX, Chou JF, Liu YM, Zhang QY, Sun SQ (2003) Review and prospect of the study on the subtropical anticyclone. Chin $\quad J \quad$ Atmos Sci 27:503e517. https://doi.org/10.3878/j.issn.1006-9895.2003.04.06. (in Chinese)

Xu M, et al (2006) Steady decline of East Asian monsoon winds, 1969-2000: evidence from direct ground measurements of wind speed. J Geophys Res Atoms 111:D24111. https://doi.org/10.1029/2006JD007337. 
$634 \mathrm{Xu} \mathrm{XP}$, et al (2019) Strengthened linkage between midlatitudes and Arctic in boreal winter.

635 Clim Dyn 53:3971-3983. https://doi.org/10.1007/s00382-019-04764-7.

636 Xue F (2001) Interannual to Interdecadal variation of East Asian summer monsoon and its

637 association with the global atmospheric circulation and sea surface temperature. Adv Atmos

638 Sci 18:567-575. https://doi.org/10.1007/s00376-001-0045-x.

639 Yasunaka S, Hanawa K (2006) Interannual Summer Temperature Variations over Japan and

640 Their Relation to Large-Scale Atmospheric Circulation Field. J Meteorol Soc Japan 84:641-652. https://doi.org/10.2151/jmsj.84.641.

642

Ye X, Zhang W, Luo M (2016) The North Pacific Gyre Oscillation and East Asian summer precipitation. Atmos Sci Lett 17:531-537. https://doi.org/10.1002/asl.688.

Ying M, Sun SQ (2000) A study on the response of subtropical high over the western Pacific on the SST anomaly. Chin J Atmos Sci 24:193-206. https://doi.org/10.1007/s10011-000-0335-3. (in Chinese)

Yu L (2013) Potential correlation between the decadal East Asian summer monsoon variability and the Pacific decadal oscillation. Atmos Ocean Sci Lett 6:394-397. https://doi.org/10.3878/j.issn.1674-2834.13.0040.

Yu RC, Wang B, Zhou TJ (2004) Tropospheric cooling and summer monsoon weakening trend over East Asia. Geophys Res Lett 31(22):L22212. https://doi.org/10.1029/2004GL021270.

Yu RC, Zhou TJ (2007) Seasonality and three-dimensional structure of interdecadal change in the East

Asian

monsoon.

J. Clim

20(21):5344-5355. https://doi.org/10.1175/2007JCLI1559.1. 

South Indian Ocean. Clim Dyn 48(3-4):1125-1139. https://doi.org/10.4172/2157-7617.C1.027.

Zhang RH, Sumi A, Kimoto M (1999) A diagnostic study of the impact of El Nin o on the precipitation in China. Adv Atmos Sci 16:229-241. https://doi.org/10.1007/BF02973084.

Zhang RH, Zuo Z (2011) Impact of spring soil moisture on surface energy balance and summer monsoon circulation over East Asia and precipitation in East China. J. Clim 24(13):3309_ 3322. https://doi.org/10.1175/2011JCLI4084.1.

Zhao P, Zhang XD, Zhou XJ, Ikeda M, Yin YH (2004) The Sea Ice Extent Anomaly in the 665 North Pacific and Its Impact on the East Asian Summer Monsoon Rainfall. J Clim 17(17):3434-3447. https://doi.org/10.1175/15200442(2004)017<3434:TSIEAI>2.0.CO;2.

Zhou TJ et al (2009) Why the western pacific subtropical high has extended westward since the late 1970s. J. Clim 22(8):2199-2215. https://doi.org/10.1175/2008JCLI2527.1.

Zhou TJ, Wu B (2017) Decadal climate prediction: Scientific frontier and challenge. Adv Earth Sci 32:331-341. https://doi.org/10.11867/j. issn.1001-8166.2017.04.0331. (in Chinese)

Zhu YL, Wang HJ, Zhou W, Ma JH (2010) Recent changes in the summer precipitation pattern in East China and the background circulation. Clim Dyn 36(7-8):1463-1473. https://doi.org/10.1007/s00382-010-0852-9. temperature tripole on the East Asian summer monsoon. Adv Atmos Sci 30(4):1173-1186. https://doi.org/10.1007/s00376-012-2125-5. 
680 Table 1: The predictive skill of the statistical model combined with the increment method for the DI_EASMI 681 and EASMI.

682 
Fig. 1 a Decadal EASMI during 1918-2010 and b DI_EASMI during 1921-2010

Fig. 2 Skewness coefficient (red bar) and kurtosis coefficient (blue bar) of decadal EASMI and DI_EASMI. "0" represents decadal EASMI, "1", "2", and "3" represent 1-year, 2-year, and 3-year increment of decadal EASMI, respectively

689

Fig. 3 Correlation coefficients between DI_EASMI during 1921-2010 and the leading DI of predictors (a 3year leading sea surface temperature in summer (June to August); b 4-year leading Bonin high in Autumn (September to November). Dotted areas indicate values significant at the 95\% confidence level by the student's t-test, and the boxes indicate the key areas of the predictors, including DI_SSTI $\left(10^{\circ} \mathrm{S}-4^{\circ} \mathrm{N}, 170^{\circ} \mathrm{E}-\right.$ $\left.160^{\circ} \mathrm{W}\right)$ and $\left(0^{\circ}-16^{\circ} \mathrm{N}, 129^{\circ} \mathrm{E}-155^{\circ} \mathrm{E}\right)$, DI_BH $\left(32^{\circ} \mathrm{N}-50^{\circ} \mathrm{N}, 130^{\circ} \mathrm{E}-165^{\circ} \mathrm{E}\right)$

Fig. 4 a Correlation coefficient between DI_EASMI during 1921-2010 and the leading 5-year DI of sea ice concentration in summer (June to August). The box indicates the key area of the predictor, and area-weighted regionally averaged DI_SIC $\left(77^{\circ} \mathrm{S}-80^{\circ} \mathrm{N}, 70^{\circ} \mathrm{E}-90^{\circ} \mathrm{E}\right)$ is used as a predictor. Correlation coefficient of the summer DI_SIC during 1916-2005 with b the spring (March to May) DI of snow cover during 1921-2010 and $\mathbf{c}$ the summer DI of $850 \mathrm{hPa}$ geopotential height during 1921-2010. Dotted areas indicate values significant at the $95 \%$ confidence level by the student's t-test

Fig. 5 Time series of DI_EASMI during 1921-2010 (black line) and 3-year leading DI_SSTI (blue line), 4year leading DI_BH (green line) and 5-year leading DI_SIC (red line)

Fig. 6 25-year running correlation between DI_EASMI during 1921-2010 and leading DI of predictors (a BH, b SSTI, c SIC). The dotted line is at the $95 \%$ confidence level by the student's t-test, and the effective sample numbers are 22,23 , and 22 , respectively

Fig. 7 Predictions of a, d DI_EASMI and $\mathbf{b}, \mathbf{e}$ EASMI and $\mathbf{c}, \mathbf{f}$ the results of the moving t-test with a 10-year moving window of EASMI (a, b, $\mathbf{c}$ results of the cross validation during 1921-2010; d, e, $\mathbf{f}$ results of independent hindcast during 1980-2010; the light pink shading indicates the 95\% confidence interval of the prediction. The value in the upper right corner is the correlation coefficient/MSSS between observations and predictions; the thin solid lines in $\mathbf{c}$ and $\mathbf{f}$ are significant at the $95 \%$ confidence levels)

Fig. 8 a Correlation coefficient between DI_EASMI during 1990-2018 and the leading 4-year summer (June to August) DI of sea ice cover. The box indicates the key area of the predictor, and area-weighted regionally averaged DI_SIC $\left(71^{\circ}-76^{\circ} \mathrm{N}, 150^{\circ}-178^{\circ} \mathrm{E}\right)$ is used as a predictor. b Correlation coefficient between summer DI_SIC during 1986-2014 and the spring (March to May) DI of sea surface temperature during 1990-2018. 
Fig. 9 Correlation coefficient between DI_EASMI during 1990-2018 and the 4-year leading DI of sea surface temperature in summer (June to August). Dotted areas indicate values significant at the 95\% confidence level by the student's t-test, and the box indicates the key area of the predictor, including DI_SST $\left(35^{\circ} \mathrm{S}-44^{\circ} \mathrm{S}, 70^{\circ} \mathrm{E}-110^{\circ} \mathrm{E}\right)$

Fig. 10 Time series of DI_EASMI during 1990-2018 (black line) and 4-year leading DI_SST (blues line) and DI_SIC (red line) during 1990-2022

Fig. 11 Predictions of a,d DI_EASMI and $\mathbf{b}, \mathbf{e}$ EASMI and $\mathbf{c}$ the results of the moving t-test with a 9-year moving window of EASMI (a, b, c results of the cross validation during 1990-2018; d, e results of independent hindcast during 2011-2022; the light pink shading indicates the 95\% confidence interval of the prediction. The value in the upper right corner is the correlation coefficient/MSSS between observations and predictions; the thin solid lines in c are significant at the $95 \%$ confidence levels by the student's t-test)

Fig. 12 Re-predictions of EASMI during 1993-2022, which is obtained by adding the predicted DI_EASMI from statistical model to the EASMI prediction result three years ago from decadal increment (left of the dotted line: results of the cross validation during 1993-2013; right of the dotted line: results of the independent hindcast during 2014-2022). The light pink shading indicates the 95\% confidence interval of the prediction. The value in the upper right corner is the correlation coefficient/MSSS between observations and predictions

Fig. 13 Direct predictions of EASMI a, $\mathbf{c}$ based on statistical prediction model in the original form and $\mathbf{b}, \mathbf{d}$ the results of the moving t-test with a 10-year moving window (a, $\mathbf{c}$ results of the cross validation during 1921-2010; b, d results of independent hindcast during 1980-2010; the light pink shading indicates the 95\% confidence interval of the prediction. The value in the upper right corner is the correlation coefficient/MSSS between observations and predictions; the thin solid lines in $\mathbf{b}$ and $\mathbf{d}$ are significant at the $95 \%$ confidence levels by the student's t-test)

Fig. 14 Schematic diagram illustrating the process of predicting EASM using the decadal increment method 


\begin{tabular}{|l|l|l|l|l|}
\hline \multirow{2}{*}{} & \multicolumn{2}{|c|}{ Cross validation (1921-2010) } & \multicolumn{2}{c|}{ Independent hindcast (1980-2010) } \\
\cline { 2 - 5 } & CC & MSSS & CC & MSSS \\
\hline DI_EASMI & 0.81 & 0.65 & 0.91 & 0.81 \\
\hline EASMI & $0.90(0.65)$ & $0.78(0.42)$ & $0.87(0.76)$ & $0.72(-1.39)$ \\
\hline
\end{tabular}

751

752 Table 1: The predictive skill of the statistical model combined with the increment method for the DI_EASMI and EASMI.

754 Note: The results predicted by the statistical model in the original form are shown in parentheses. CC is the correlation coefficient and MSSS is the mean square skill score. 

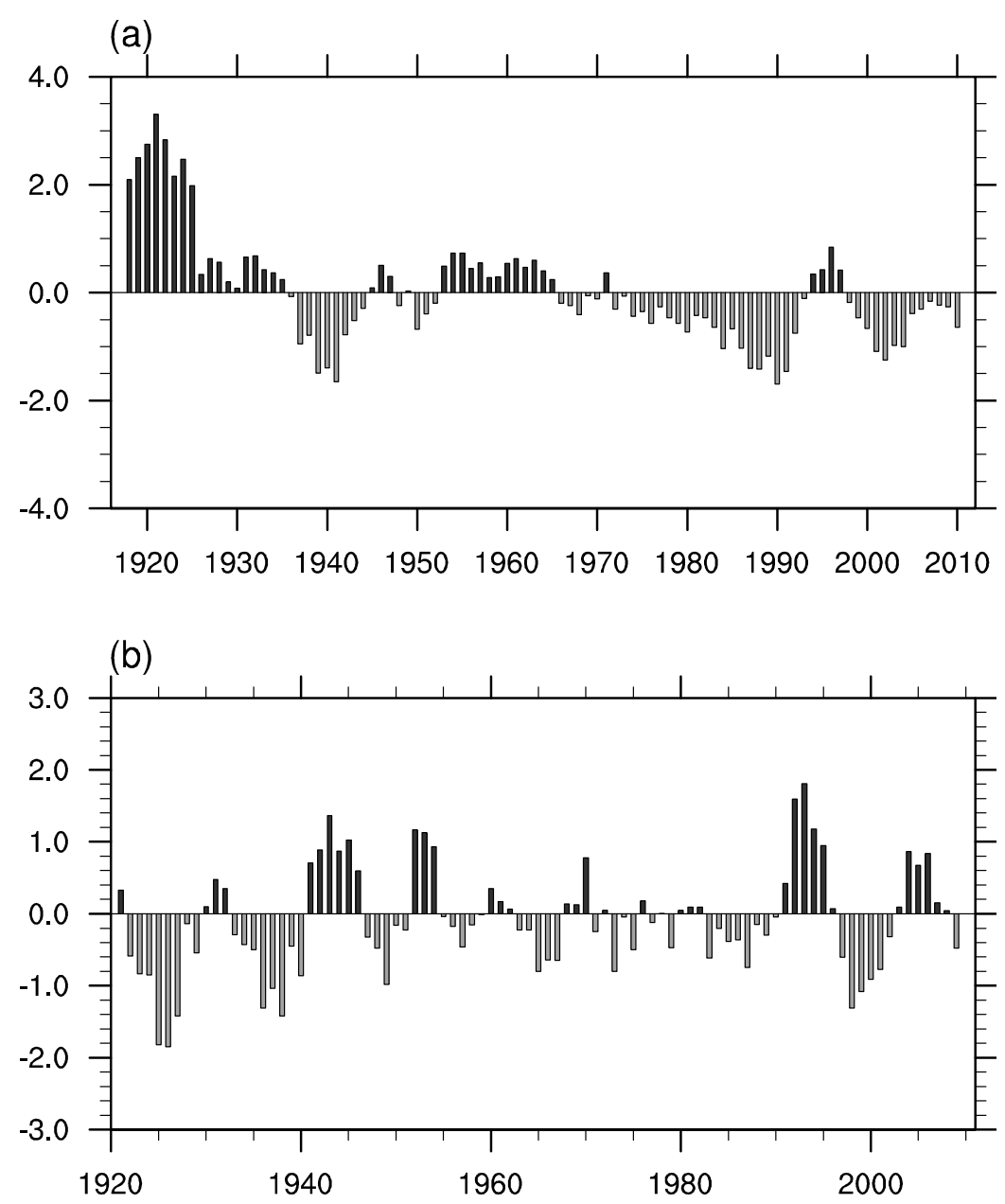

758 Fig. 1 a Decadal EASMI during 1918-2010 and b DI_EASMI during 1921-2010 


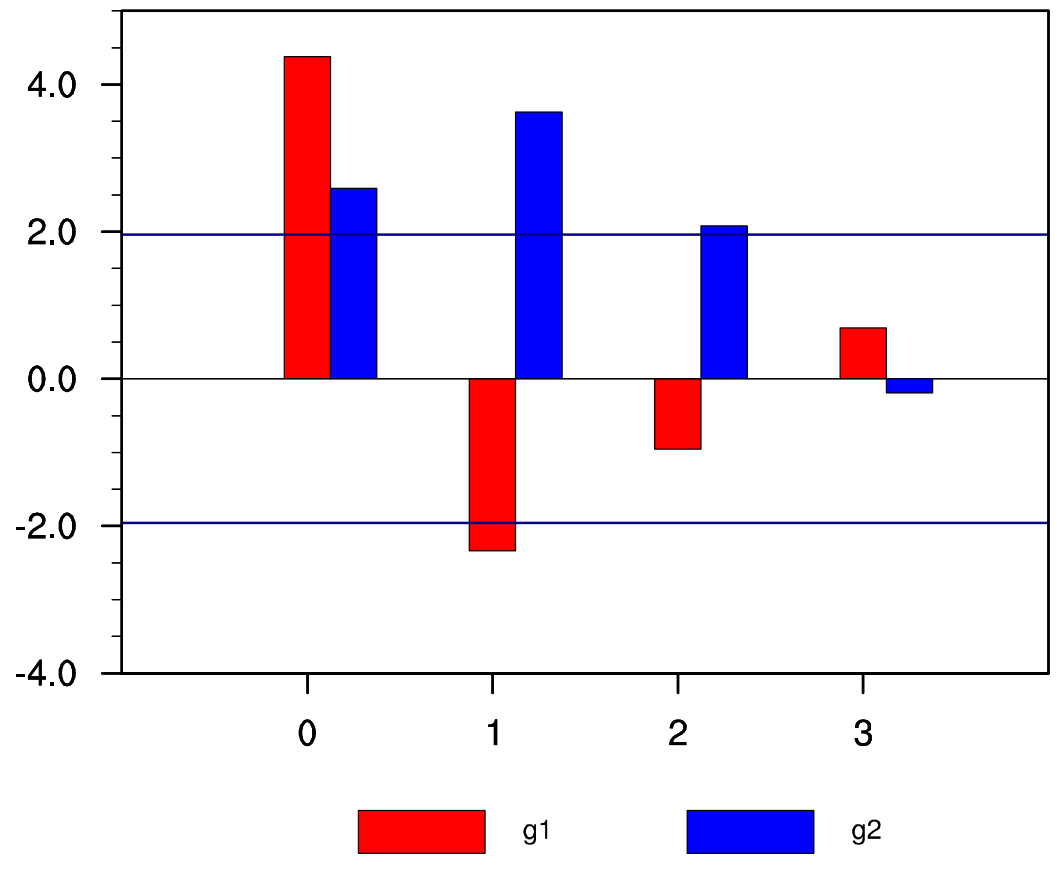

759

760 Fig. 2 Skewness coefficient (red bar) and kurtosis coefficient (blue bar) of decadal EASMI and DI_EASMI.

761 "0" represents decadal EASMI, “1”, “2”, and "3” represent 1-year, 2-year, and 3-year increment of decadal 762 EASMI, respectively 
(a)

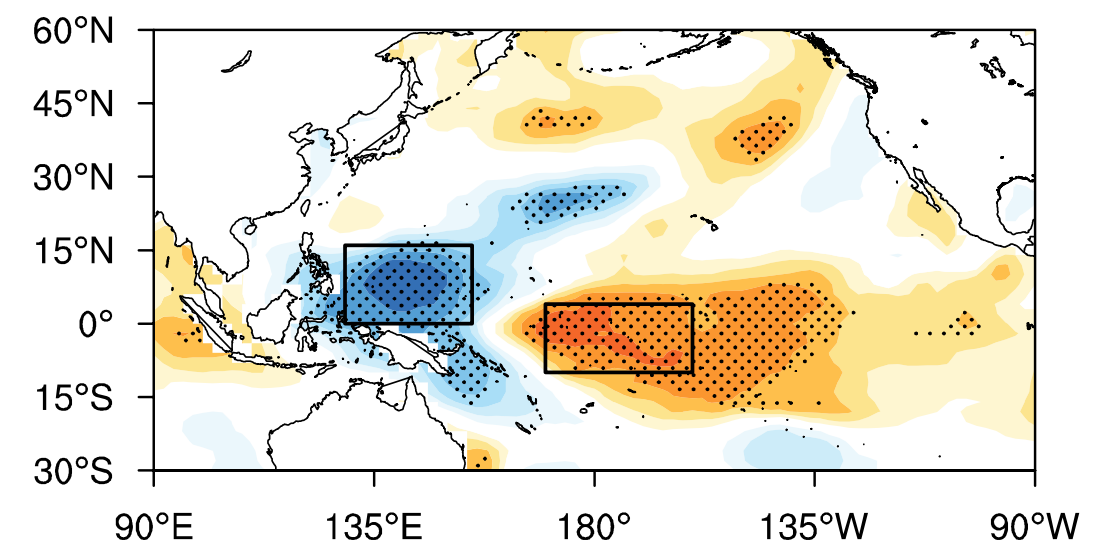

(b)

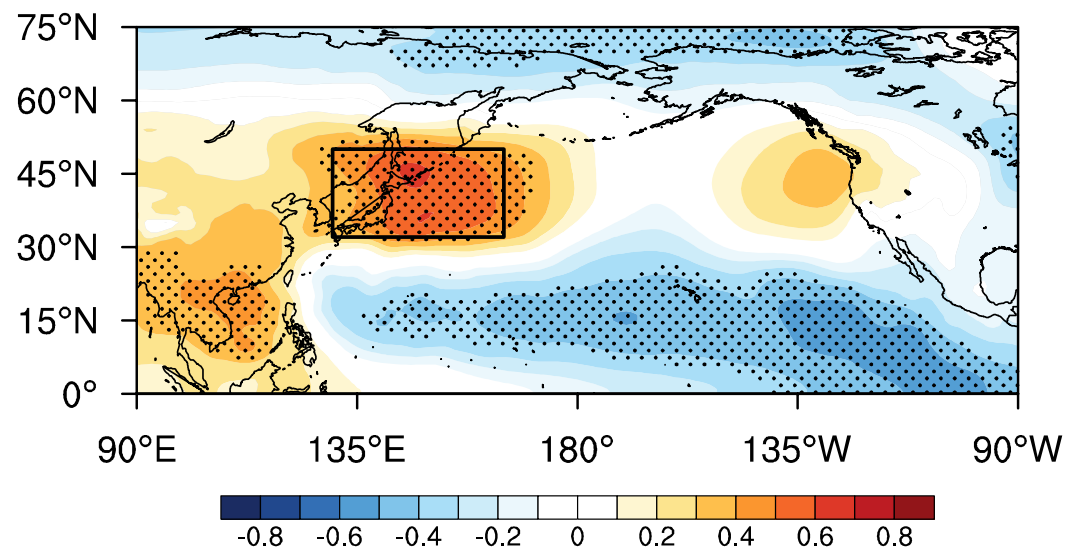

Fig. 3 Correlation coefficients between DI_EASMI during 1921-2010 and the leading DI of predictors (a 3-

765 year leading sea surface temperature in summer (June to August); b 4-year leading Bonin high in Autumn

766 (September to November). Dotted areas indicate values significant at the $95 \%$ confidence level by the

767 student's t-test, and the boxes indicate the key areas of the predictors, including DI_SSTI $\left(10^{\circ} \mathrm{S}-4^{\circ} \mathrm{N}, 170^{\circ} \mathrm{E}-\right.$

$\left.768160^{\circ} \mathrm{W}\right)$ and $\left(0^{\circ}-16^{\circ} \mathrm{N}, 129^{\circ} \mathrm{E}-155^{\circ} \mathrm{E}\right)$, DI_BH $\left(32^{\circ} \mathrm{N}-50^{\circ} \mathrm{N}, 130^{\circ} \mathrm{E}-165^{\circ} \mathrm{E}\right)$ 
(a)
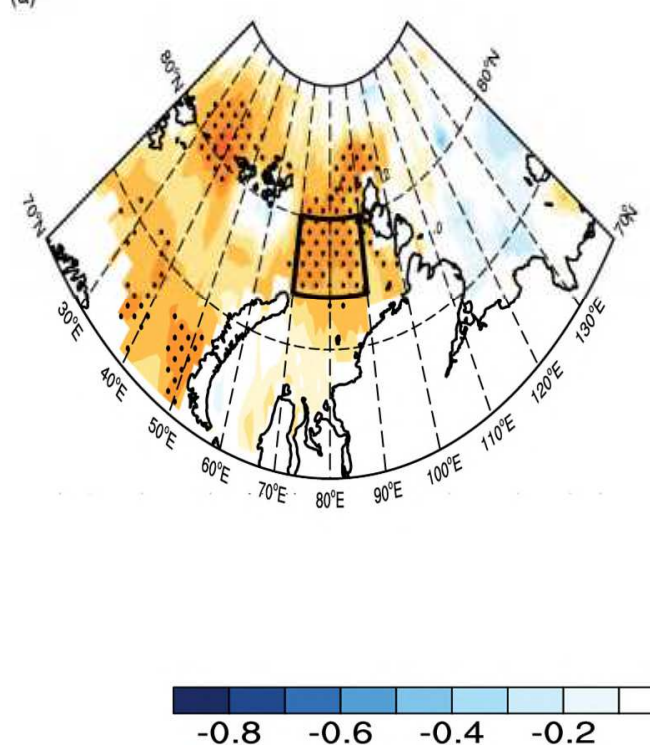
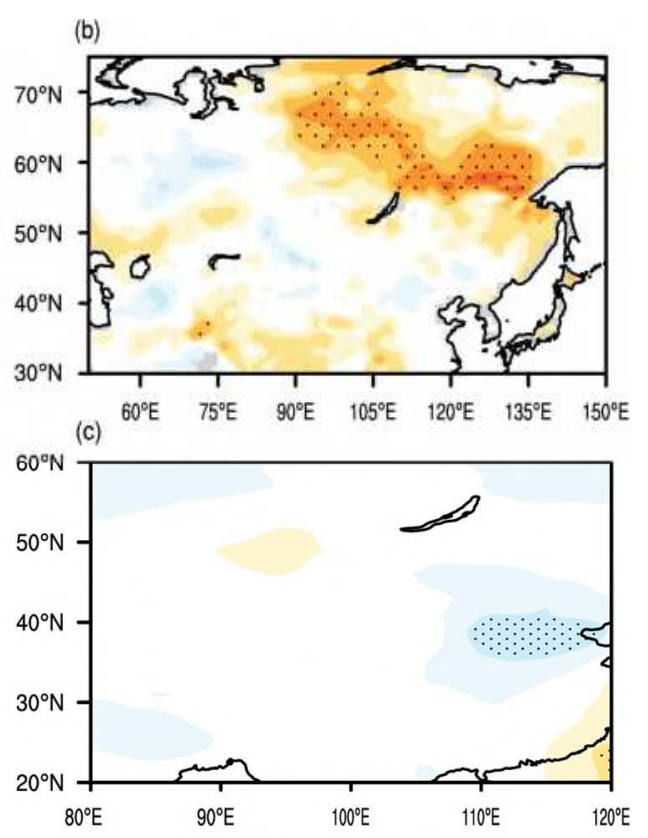
$20^{\circ} \mathrm{E}$

\section{Fig. 4 a Correlation coefficient between DI_EASMI during 1921-2010 and the leading 5-year DI of sea ice}

concentration in summer (June to August). The box indicates the key area of the predictor, and area-weighted regionally averaged DI_SIC $\left(77^{\circ} \mathrm{S}-80^{\circ} \mathrm{N}, 70^{\circ} \mathrm{E}-90^{\circ} \mathrm{E}\right)$ is used as a predictor. Correlation coefficient of the summer DI_SIC during 1916-2005 with b the spring (March to May) DI of snow cover during 1921-2010 and $\mathbf{c}$ the summer DI of $850 \mathrm{hPa}$ geopotential height during 1921-2010. Dotted areas indicate values significant at the $95 \%$ confidence level by the student's t-test 


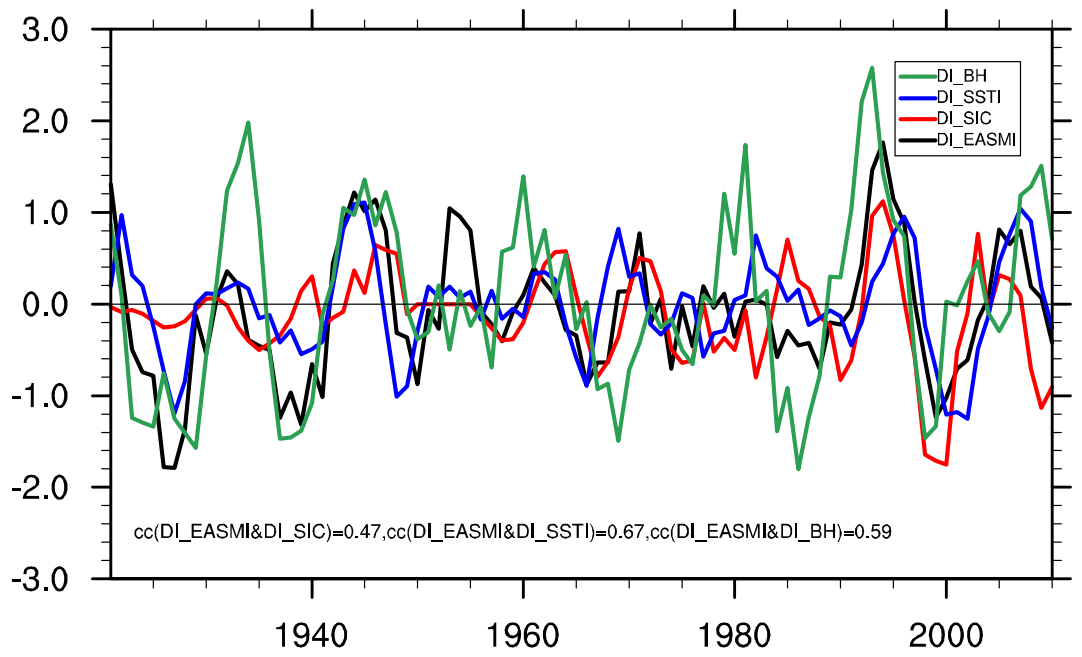

777 Fig. 5 Time series of DI_EASMI during 1921-2010 (black line) and 3-year leading DI_SSTI (blue line), 4 778 year leading DI_BH (green line) and 5-year leading DI_SIC (red line) 

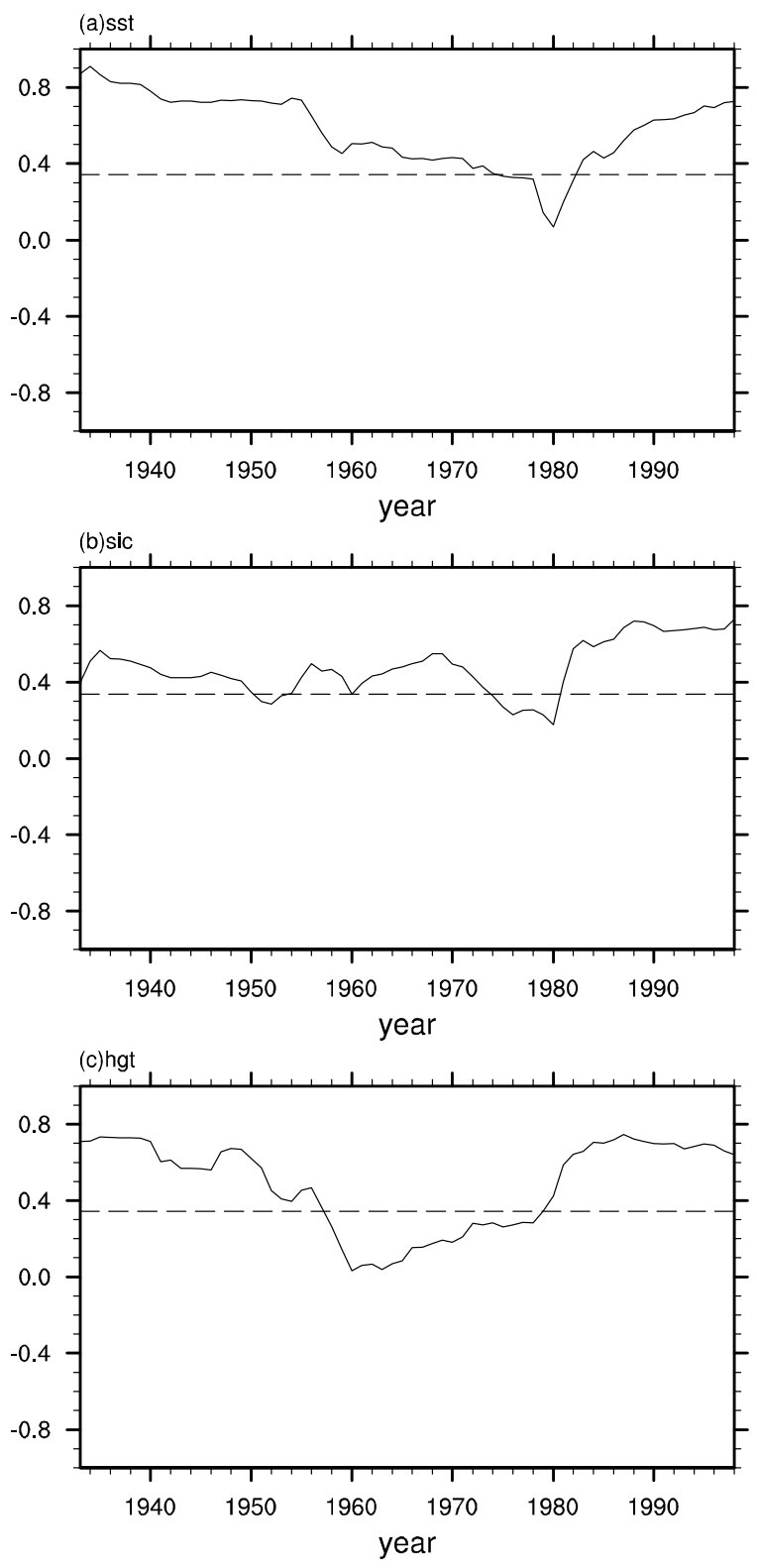

780 Fig. 6 25-year running correlation between DI_EASMI during 1921-2010 and leading DI of predictors (a 781 BH, b SSTI, c SIC). The dotted line is at the 95\% confidence level by the student's t-test, and the effective sample numbers are 22,23 , and 22 , respectively 

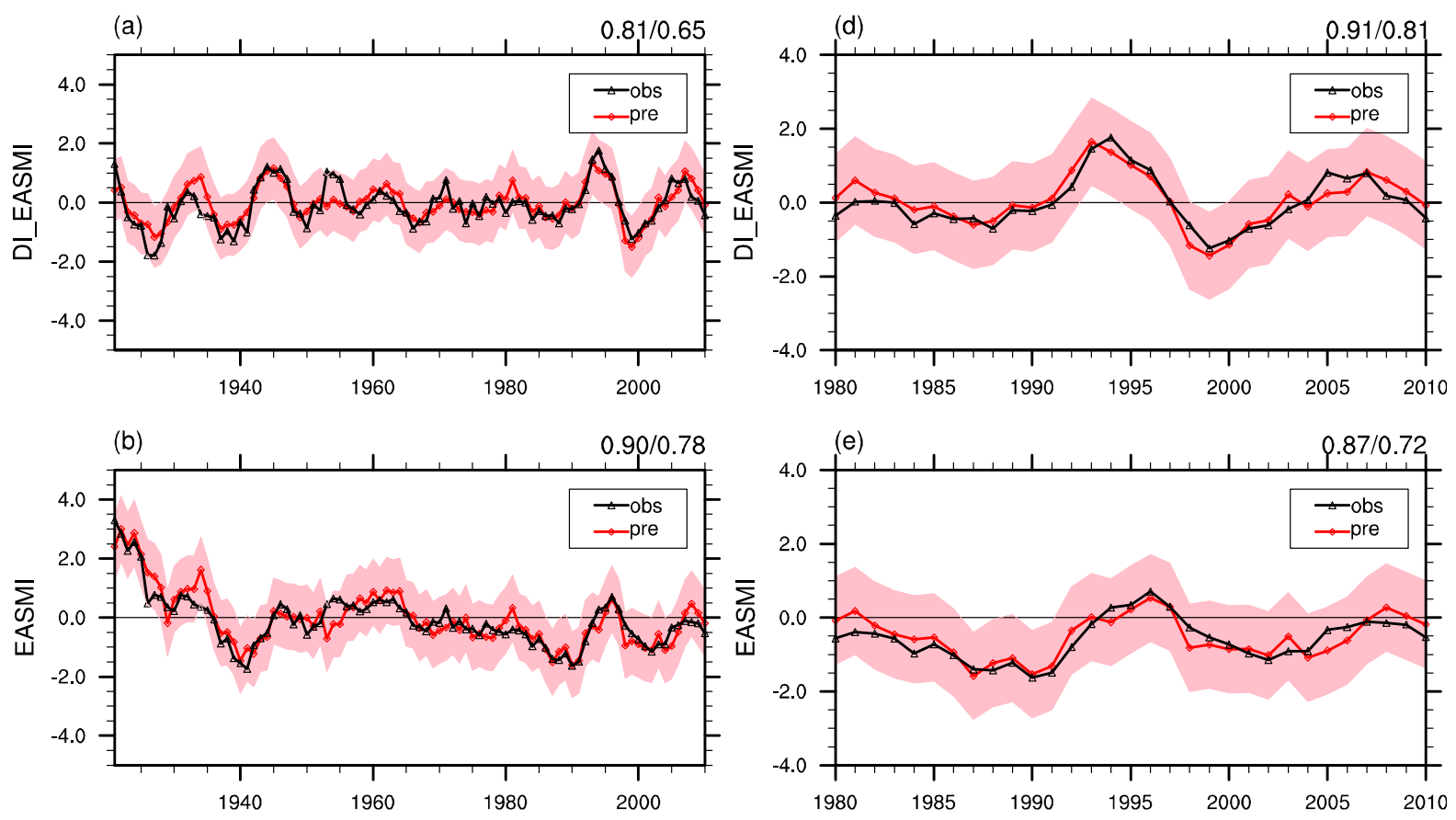

(c)
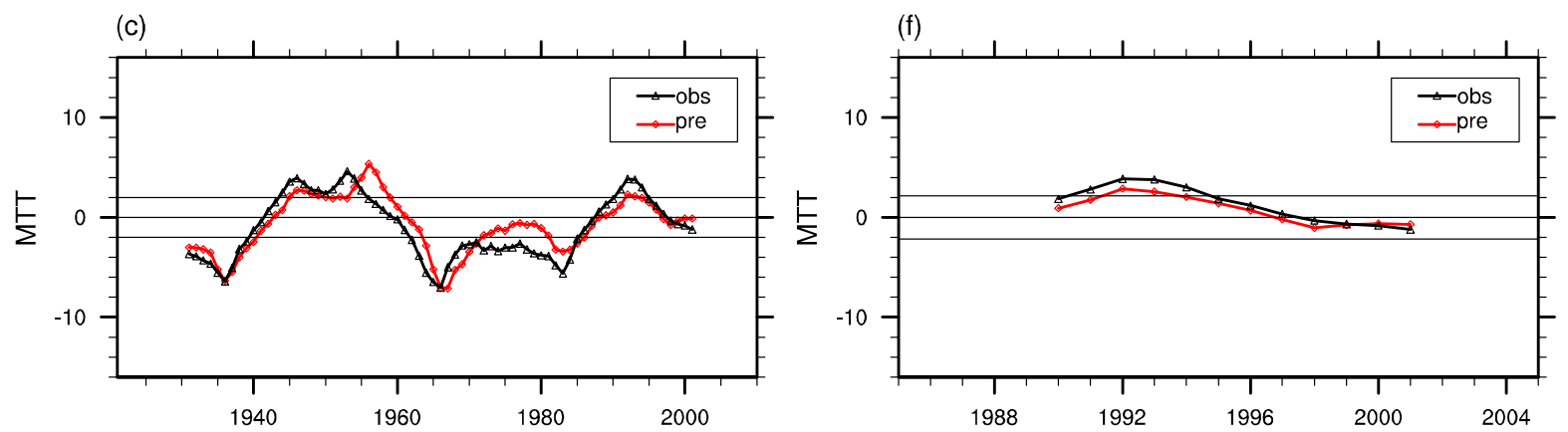

Fig. 7 Predictions of a,d DI_EASMI and $\mathbf{b}, \mathbf{e}$ EASMI and $\mathbf{c}, \mathbf{f}$ the results of the moving t-test with a 10-year moving window of EASMI (a, b, $\mathbf{c}$ results of the cross validation during 1921-2010; d, e, $\mathbf{f}$ results of independent hindcast during 1980-2010; the light pink shading indicates the 95\% confidence interval of the prediction. The value in the upper right corner is the correlation coefficient/MSSS between observations and predictions; the thin solid lines in $\mathbf{c}$ and $\mathbf{f}$ are significant at the 95\% confidence levels) 
(a)

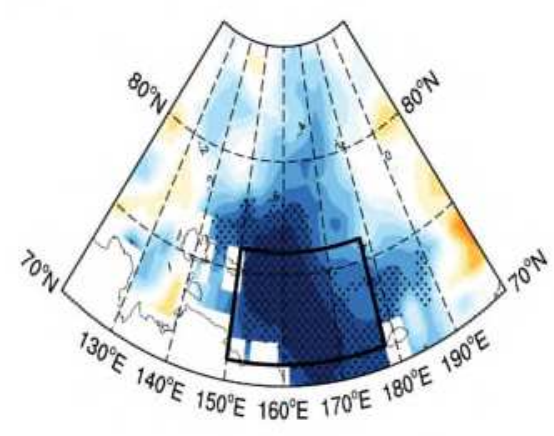

(b)

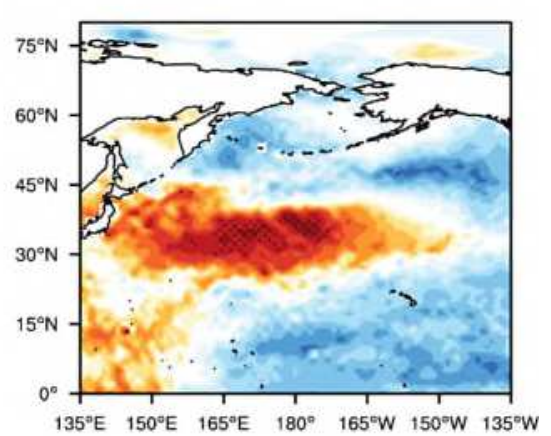

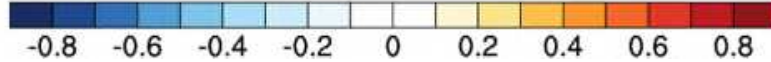

790 Fig. 8 a Correlation coefficient between DI_EASMI during 1990-2018 and the leading 4-year summer (June

791 to August) DI of sea ice cover. The box indicates the key area of the predictor, and area-weighted regionally 792 averaged DI_SIC $\left(71^{\circ}-76^{\circ} \mathrm{N}, 150^{\circ}-178^{\circ} \mathrm{E}\right)$ is used as a predictor. b Correlation coefficient between summer 793 DI_SIC during 1986-2014 and the spring (March to May) DI of sea surface temperature during 1990-2018.

794 Dotted areas indicate values significant at the $95 \%$ confidence level by the student's t-test 


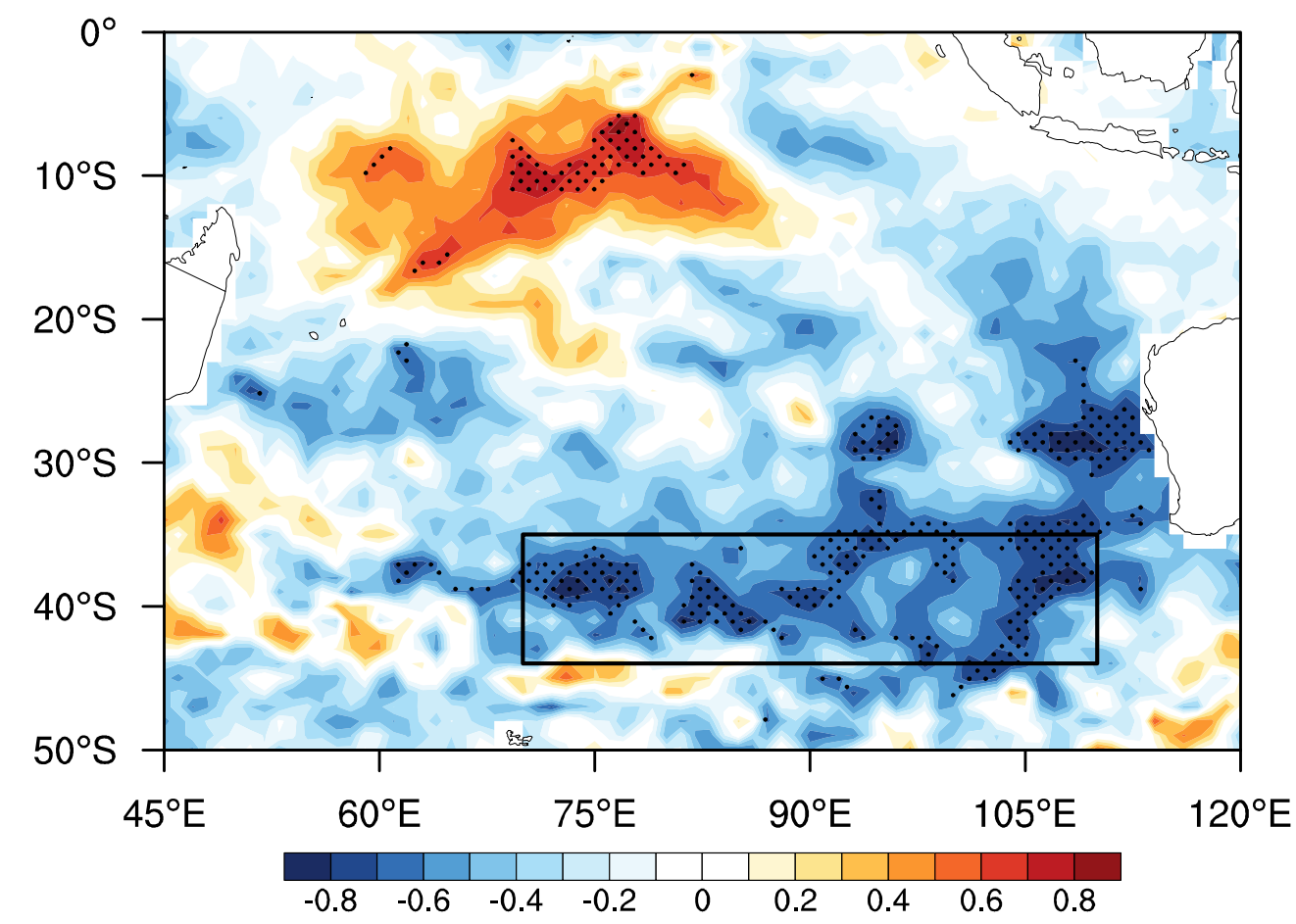

Fig. 9 Correlation coefficient between DI_EASMI during 1990-2018 and the 4-year leading DI of sea surface temperature in summer (June to August). Dotted areas indicate values significant at the 95\% confidence level by the student's t-test, and the box indicates the key area of the predictor, including DI_SST $\left(35^{\circ} \mathrm{S}-44^{\circ} \mathrm{S}, 70^{\circ} \mathrm{E}-110^{\circ} \mathrm{E}\right)$ 


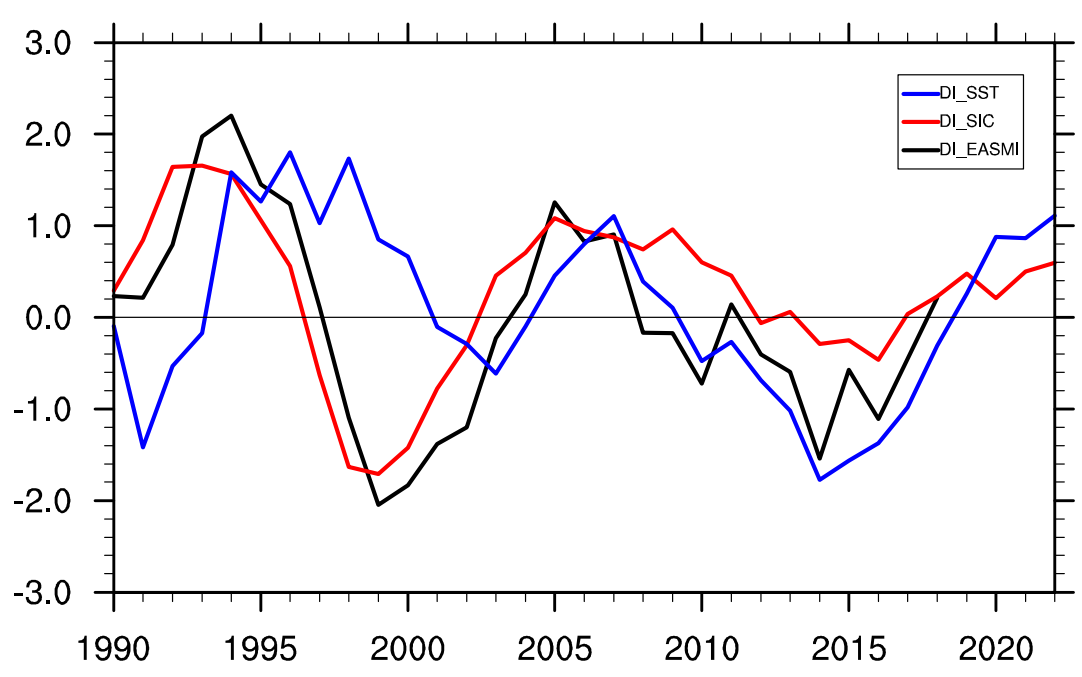

801 Fig. 10 Time series of DI_EASMI during 1990-2018 (black line) and 4-year leading DI_SST (blues line) 802 and DI_SIC (red line) during 1990-2022 

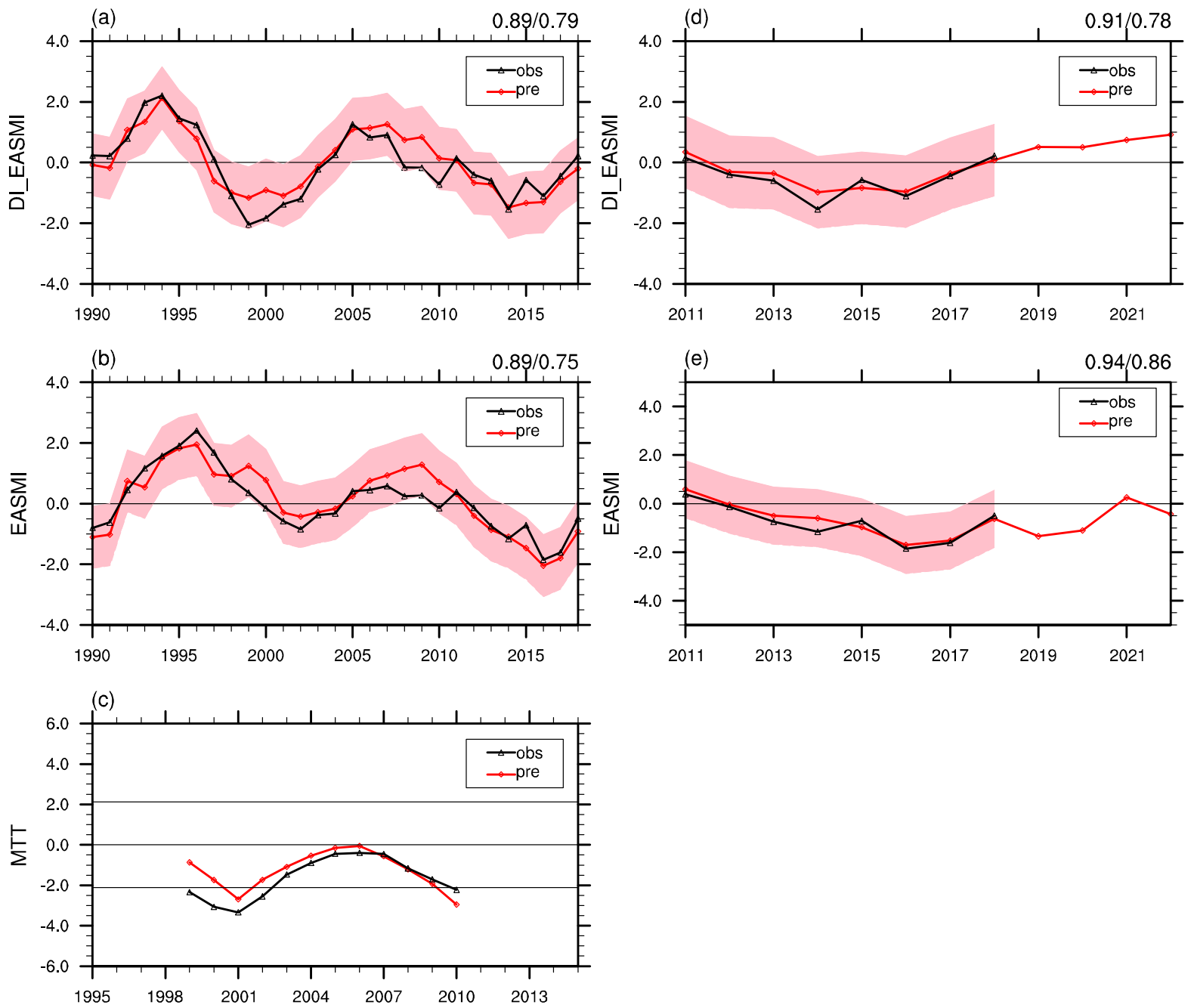

804 Fig. 11 Predictions of a,d DI_EASMI and $\mathbf{b}, \mathbf{e}$ EASMI and $\mathbf{c}$ the results of the moving t-test with a 9-year 805 moving window of EASMI (a, b, c results of the cross validation during 1990-2018; d, e results of 806 independent hindcast during 2011-2022; the light pink shading indicates the 95\% confidence interval of the prediction. The value in the upper right corner is the correlation coefficient/MSSS between observations and predictions; the thin solid lines in $\mathbf{c}$ are significant at the $95 \%$ confidence levels by the student's t-test) 


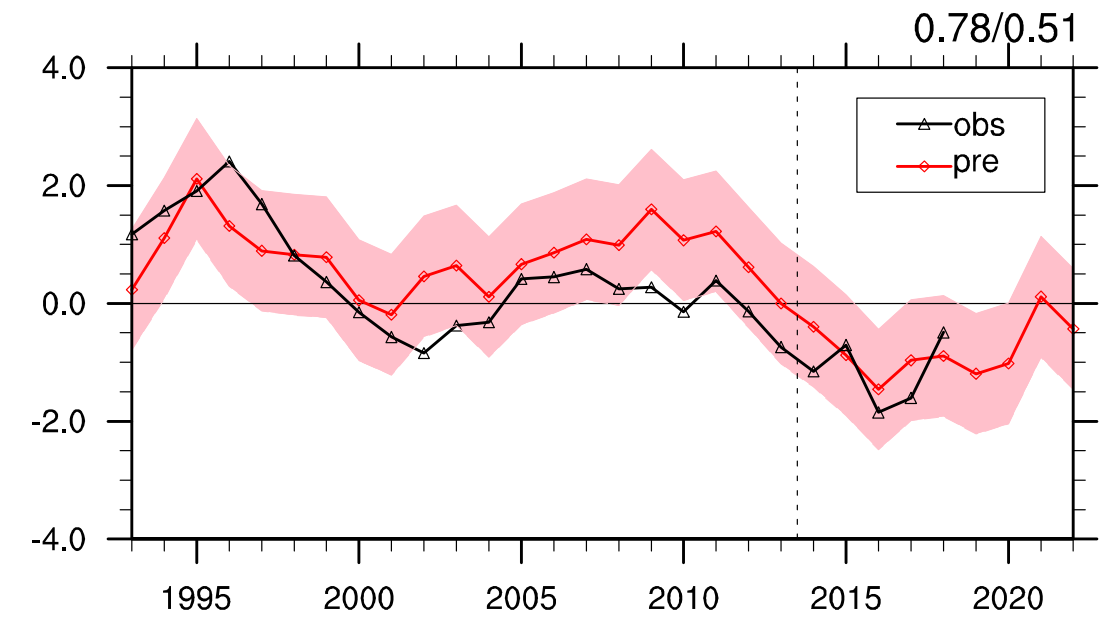

809

810 Fig. 12 Re-predictions of EASMI during 1993-2022, which is obtained by adding the predicted DI_EASMI

811 from statistical model to the EASMI prediction result three years ago from decadal increment (left of the

812 dotted line: results of the cross validation during 1993-2013; right of the dotted line: results of the

813 independent hindcast during 2014-2022). The light pink shading indicates the 95\% confidence interval of

814 the prediction. The value in the upper right corner is the correlation coefficient/MSSS between observations

815 and predictions 

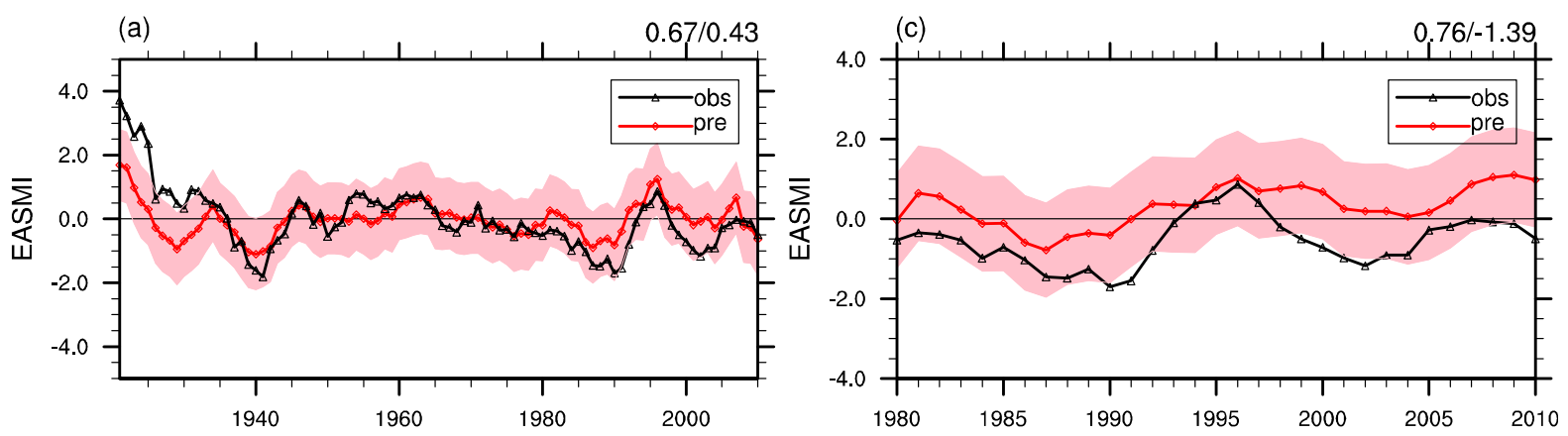

(b)
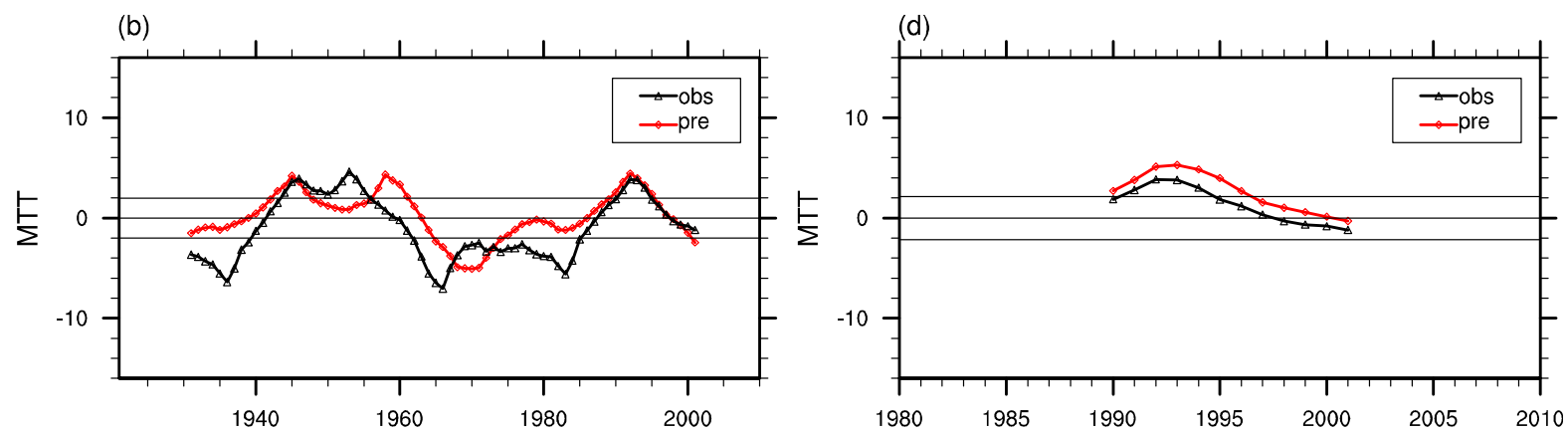

817 Fig. 13 Direct predictions of EASMI a, $\mathbf{c}$ based on statistical prediction model in the original form and $\mathbf{b}, \mathbf{d}$

818 the results of the moving t-test with a 10-year moving window (a, $\mathbf{c}$ results of the cross validation during

819 1921-2010; b, d results of independent hindcast during 1980-2010; the light pink shading indicates the 95\%

820 confidence interval of the prediction. The value in the upper right corner is the correlation coefficient/MSSS

821 between observations and predictions; the thin solid lines in $\mathbf{b}$ and $\mathbf{d}$ are significant at the $95 \%$ confidence

822 levels by the student's t-test) 


\section{Step 1. Decadal EASMI}

5-year running mean

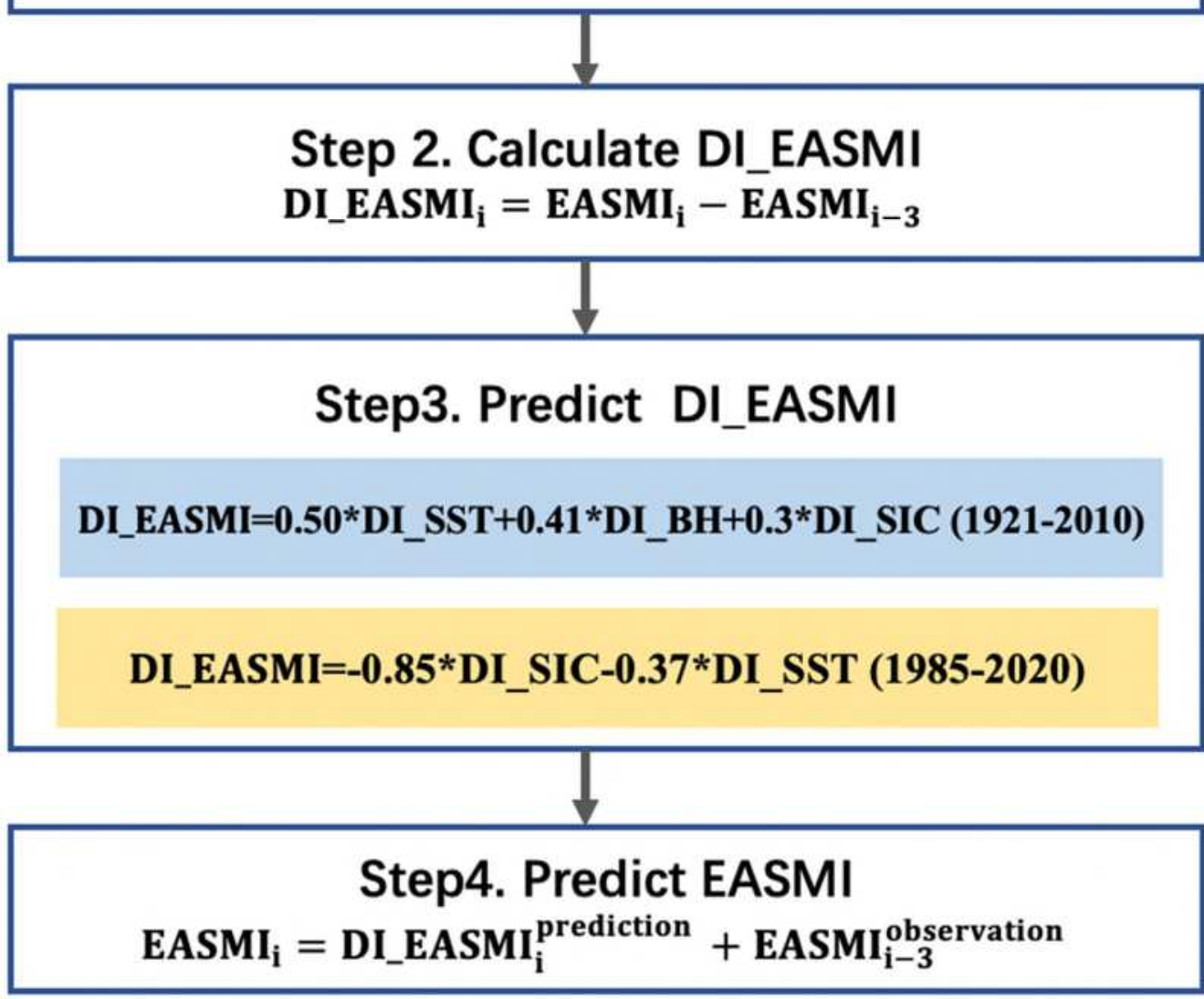

Fig. 14 Schematic diagram illustrating the process of predicting EASM using the decadal increment method 


\section{Supplementary Files}

This is a list of supplementary files associated with this preprint. Click to download.

- Supplement.docx 